M. Skorobogatiy, B. Ung, A. Mazhorova, M. Rozé, A. Dupuis, "Plastic fibers for terahertz wave guiding," ECOC 2011, Tu.6.LeCervin.1, Geneva, Switzerland, September 18-22, 2011.

\title{
Plastic fibers for terahertz wave guiding
}

Bora Ung, Alexandre Dupuis, Mathieu Rozé, Anna Mazhorova, Frédéric Désévédavy,

\section{Maksim Skorobogatiy}

Canada Research Chair in Micro and Nano-Photonics Ecole Polytechnique de Montréal, CANADA www.photonics.phys.polymtl.ca 


\section{Standard solid core TIR fiber in THz}

Terahertz: $v=0.1-10 \mathrm{THz} \quad<=>\lambda=3000-30 \mu \mathrm{m}$

Total Internal Reflection solid-core fibers:

-Pros: Insensitive to environment (humidity, dust, etc.)

-Cons: High loss, high group velocity dispersion

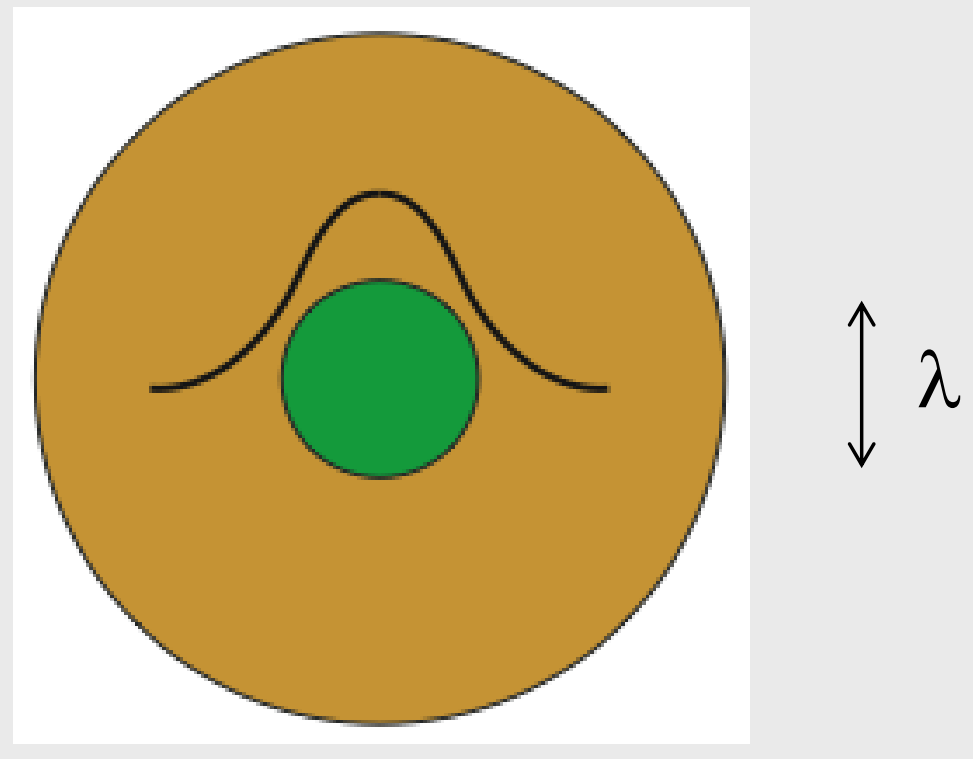




\section{Bulk polyethylene (PE) THz optical properties}

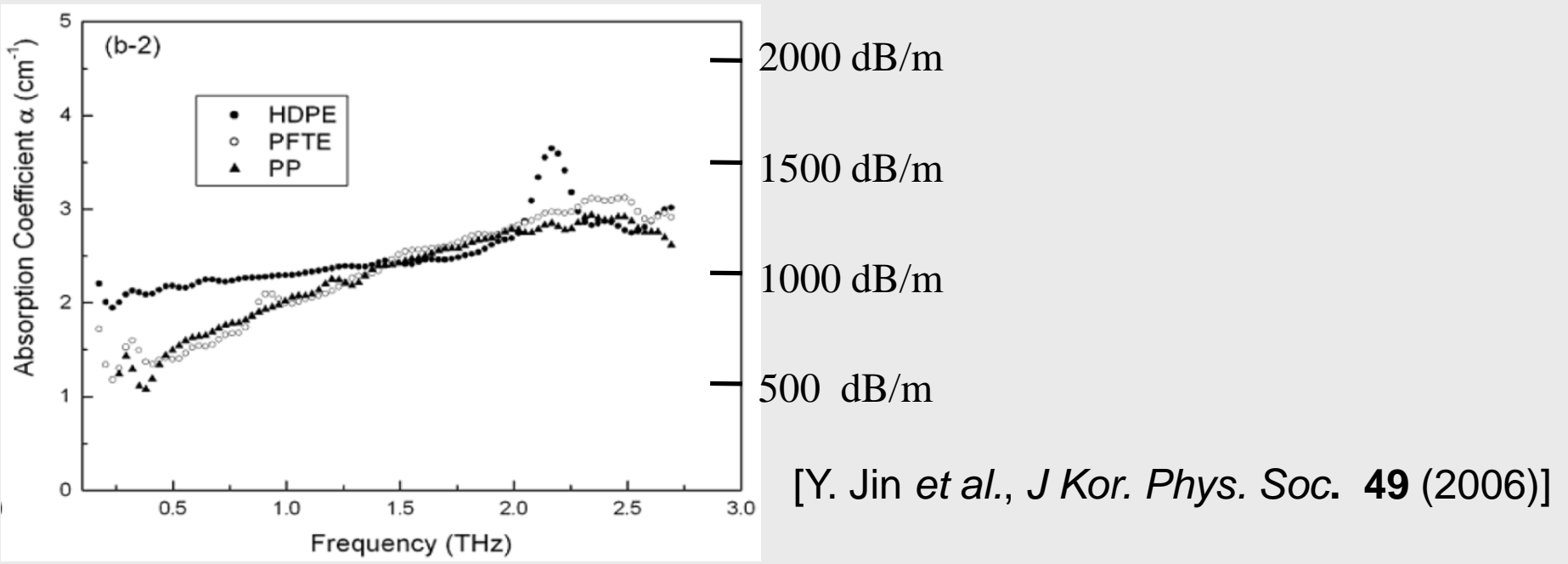

a)

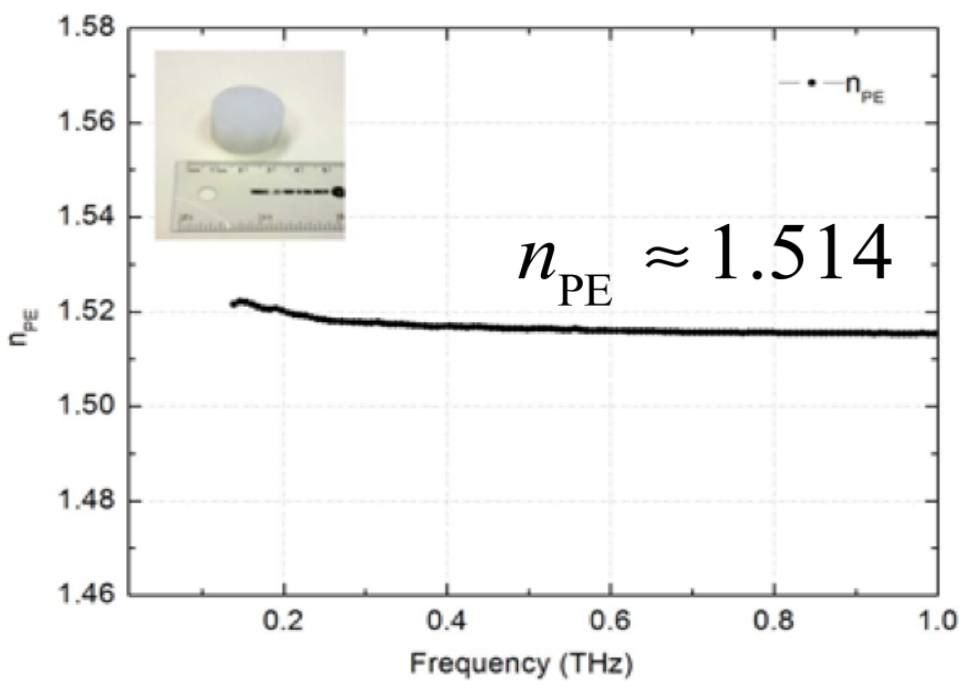

b)

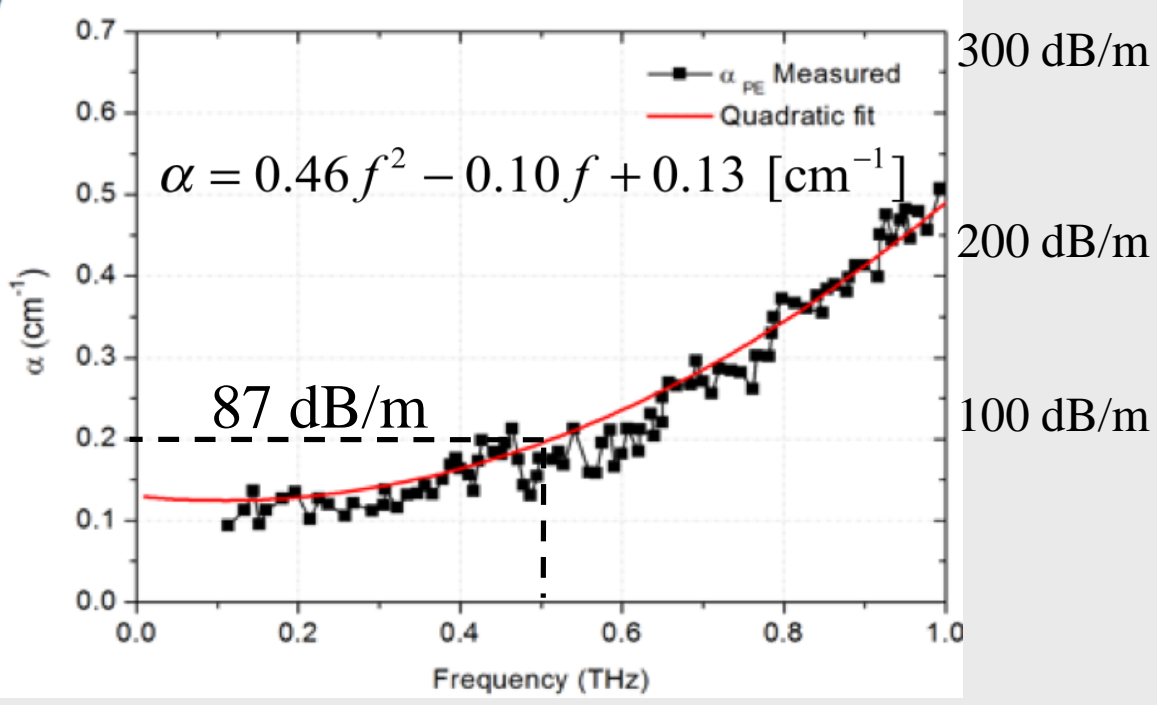

[A. Mazhorova, J. Gu, A. Dupuis, M. Peccianti, O. Tsuneyuki, R. Morandotti, H. Minamide, M. Tang, Y. Wang, H. Ito, and M. Skorobogatiy, "Composite THz materials using aligned metallic and semiconductor microwires, experiments and interpretation," G, Express, 18 (2010)] 


\section{Lowering absorption loss in TIR fibers}

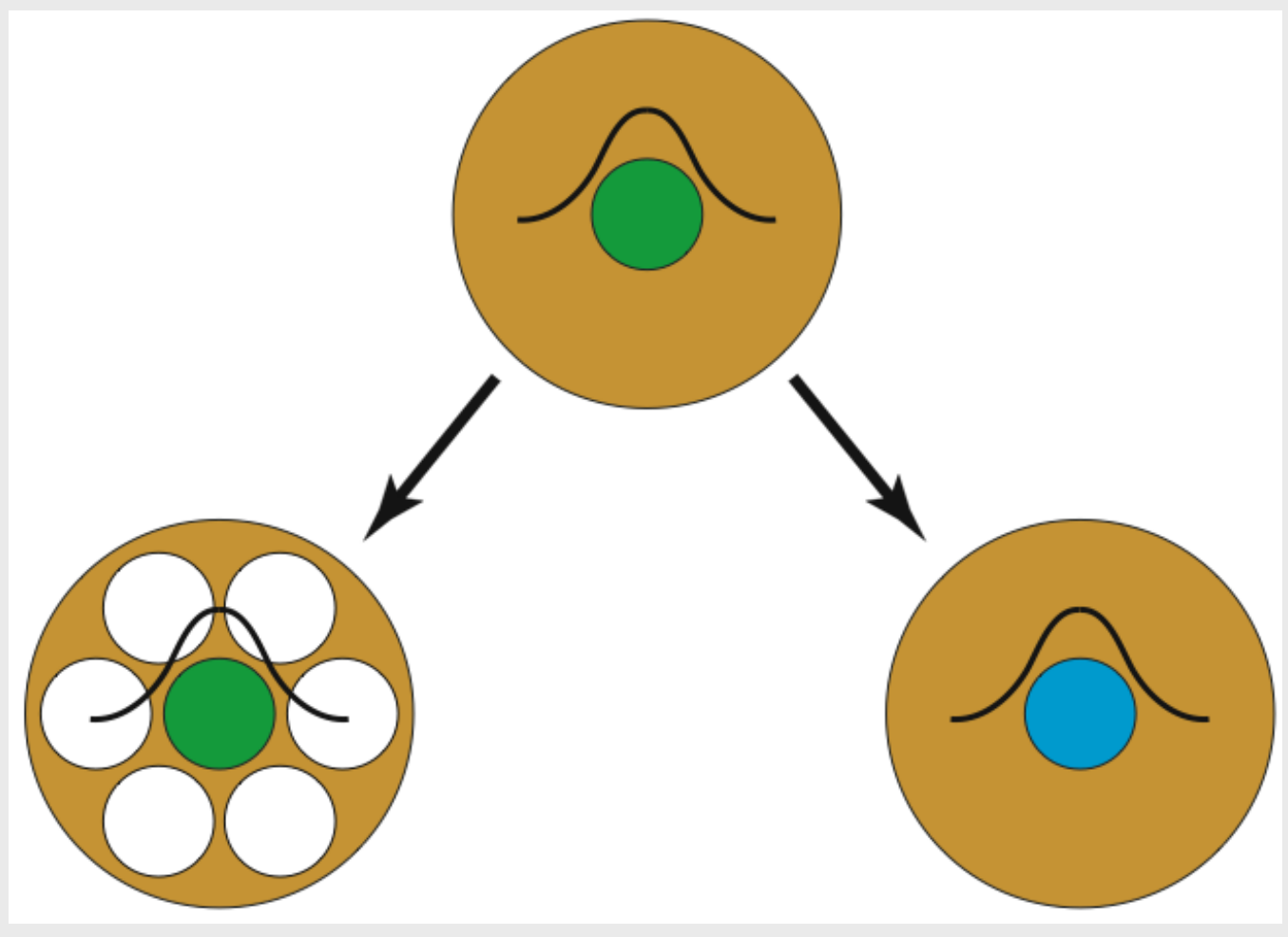

Lower loss dielectrics

by chemistry or composite materials

Holes filled with dry gas 
Lowering absorption loss in fibers.

Hollow core guidance.

Metallized capillaries

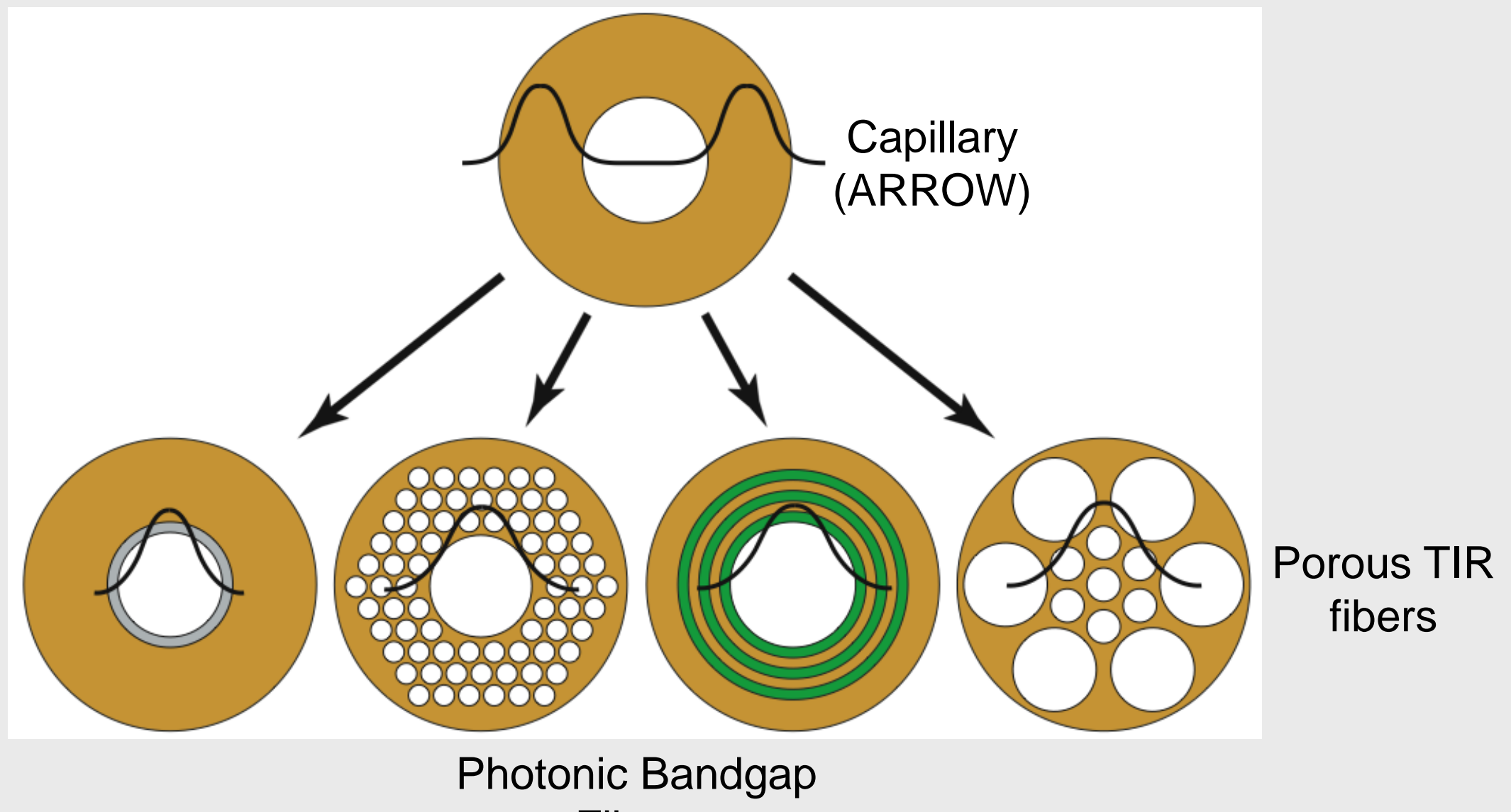

Fibers 
Plastic fibers for terahertz waves

\section{studied in our group}

\section{$\underline{\text { SOLID CORE }}$}

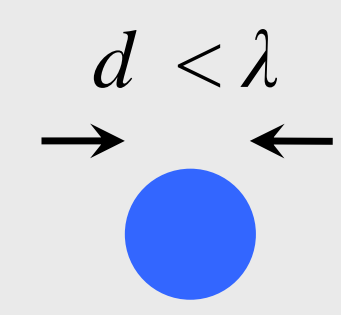

subwavelength core
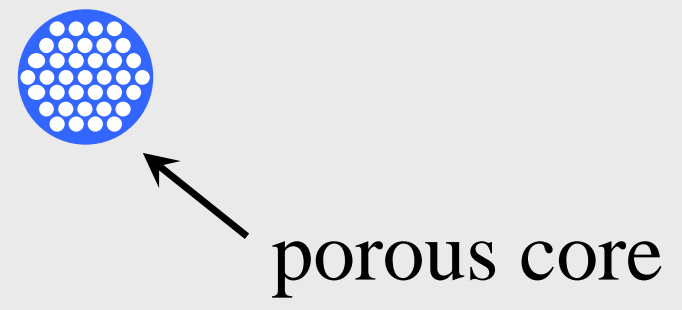

\section{PCF}

$$
\Lambda<<\lambda
$$

\section{HOLLOW CORE}

$$
\alpha \sim \frac{1}{r_{\text {core }}^{3} \nu^{2}}
$$

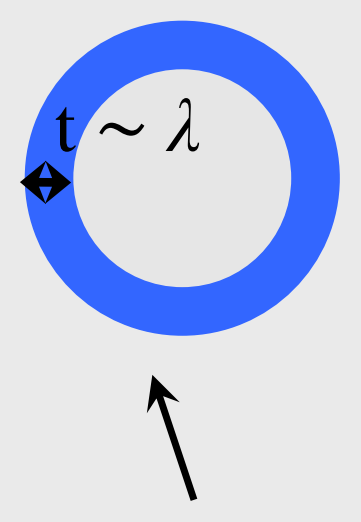

ARROW fiber
$\Lambda \sim \lambda$

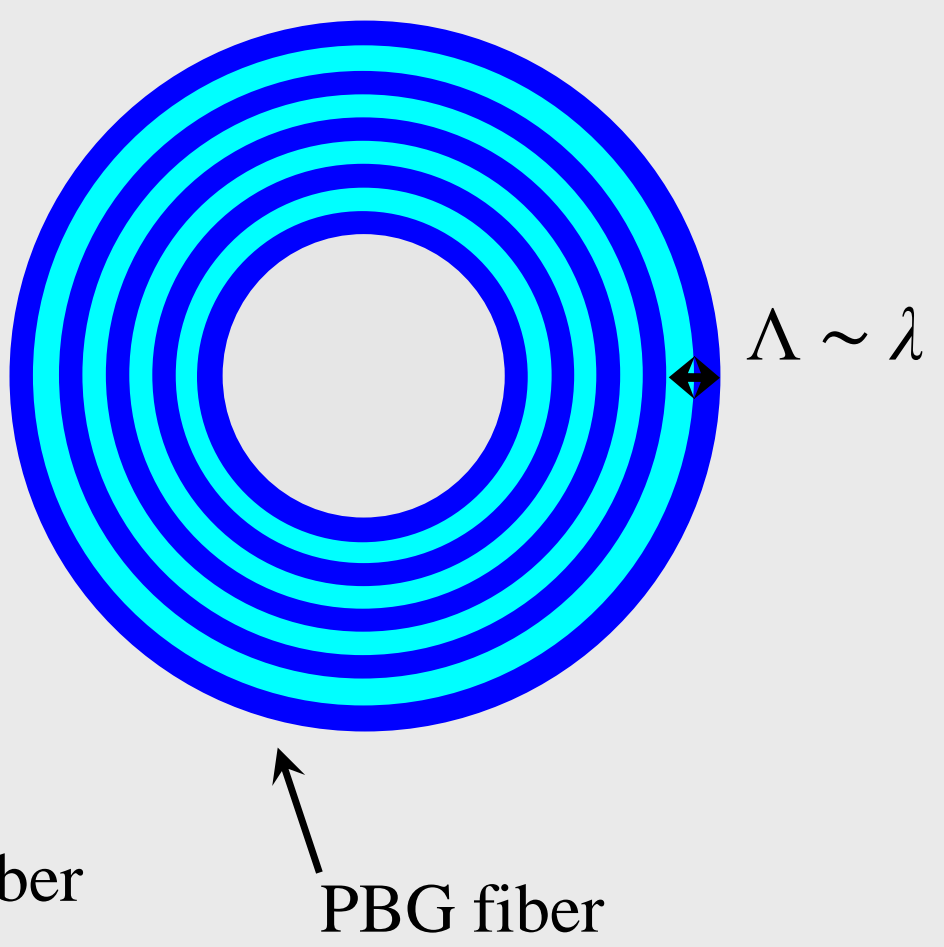




\section{Subwavelength dielectric fibers}

solid core

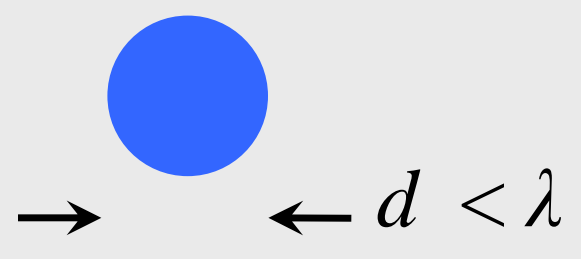

$d=120 \mu \mathrm{m}$
$1 \mathrm{THz}$ porous core

$\Lambda<<\lambda$

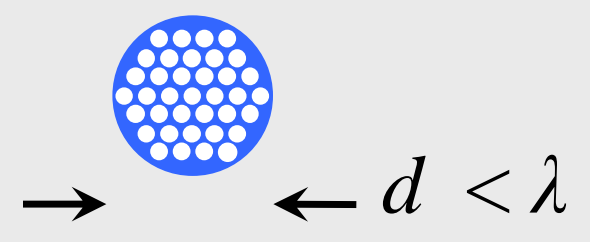

$1 \mathrm{THz}$

$$
\begin{aligned}
& f_{\alpha}=\frac{\operatorname{Re}\left(n_{\text {mat }}\right) \cdot \int_{\text {mat }}|\boldsymbol{E}|^{2} d A}{2 \int_{\text {total }} S_{z} d A} \\
& S_{z}=\frac{1}{2} \operatorname{Re}\left(\boldsymbol{E} \times \boldsymbol{H}^{*}\right) \cdot \hat{z}
\end{aligned}
$$

$$
f_{\alpha}=28 \%
$$

$$
f_{\alpha}=12 \%
$$

A. Hassani, A. Dupuis, and M. Skorobogatiy, "Low Loss Porous Terahertz Fibers Containing Multiple Subwavelength Holes," Appl. Phys. Lett. 92, 071101 (February 19, 2008). 


\section{Subwavelength porous fibers}

Lower loss dielectrics by composite materials Guidance by total internal reflection
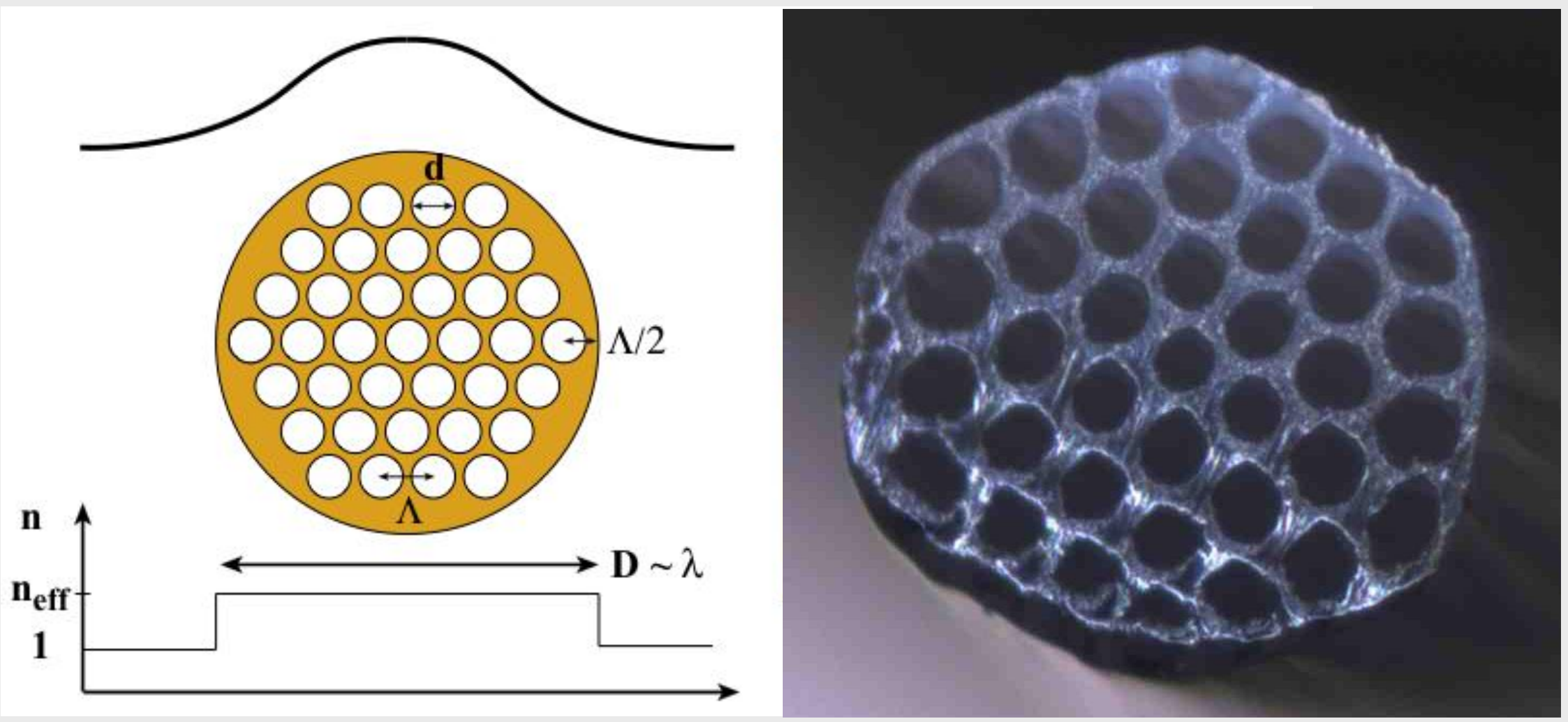

A. Hassani, A. Dupuis, and M. Skorobogatiy, "Low Loss Porous Terahertz Fibers Containing Multiple Subwavelength Holes," Appl. Phys. Lett. 92, 071101 (February 19, 2008). 


\section{Transmission and losses of porous fibers}

a)

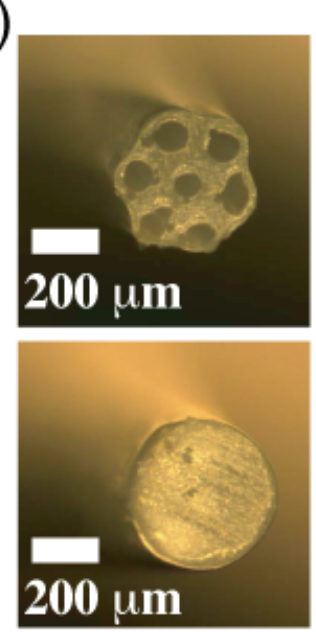

d)

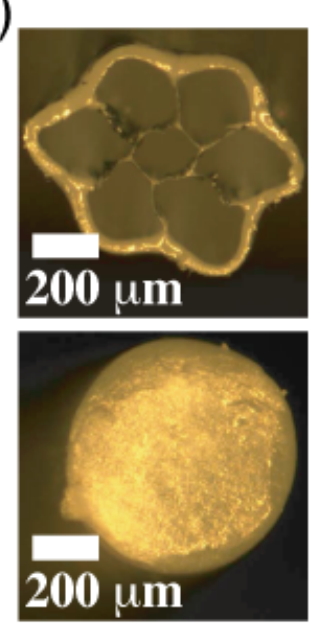

b) 1

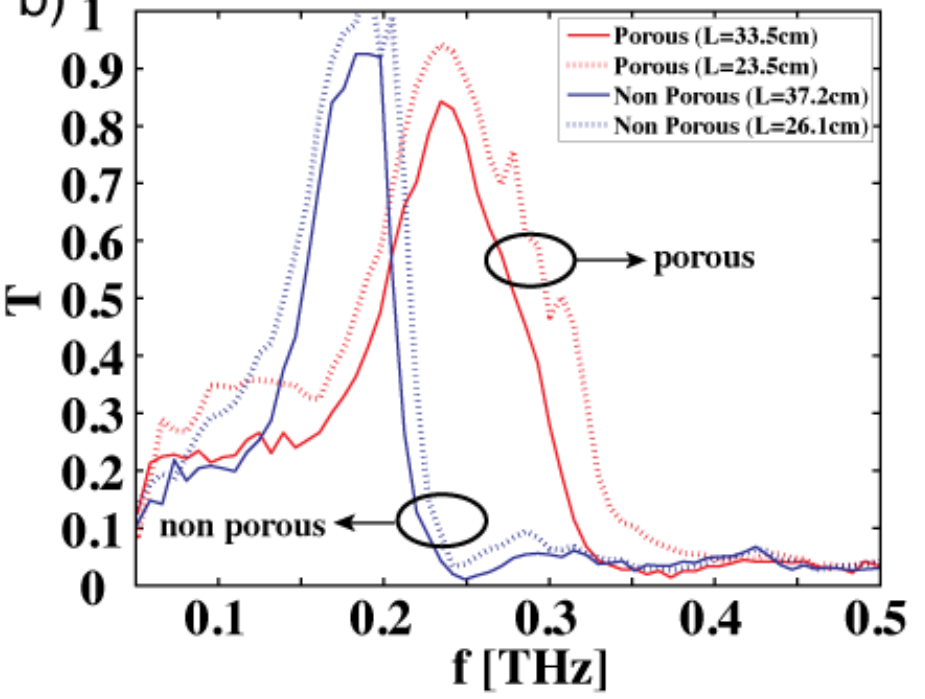

e)

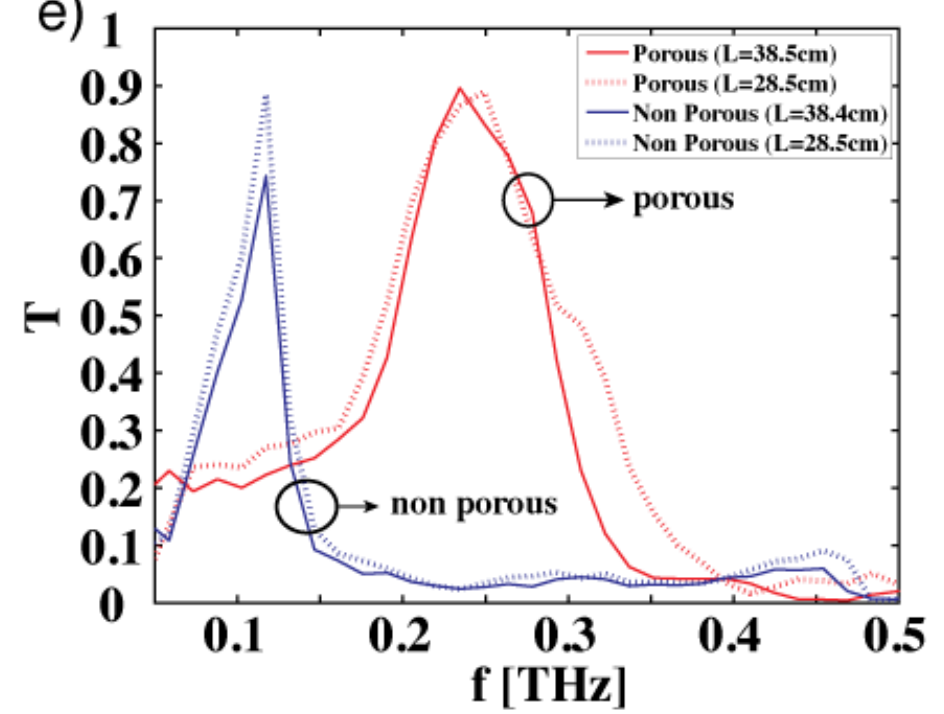

c)

f)

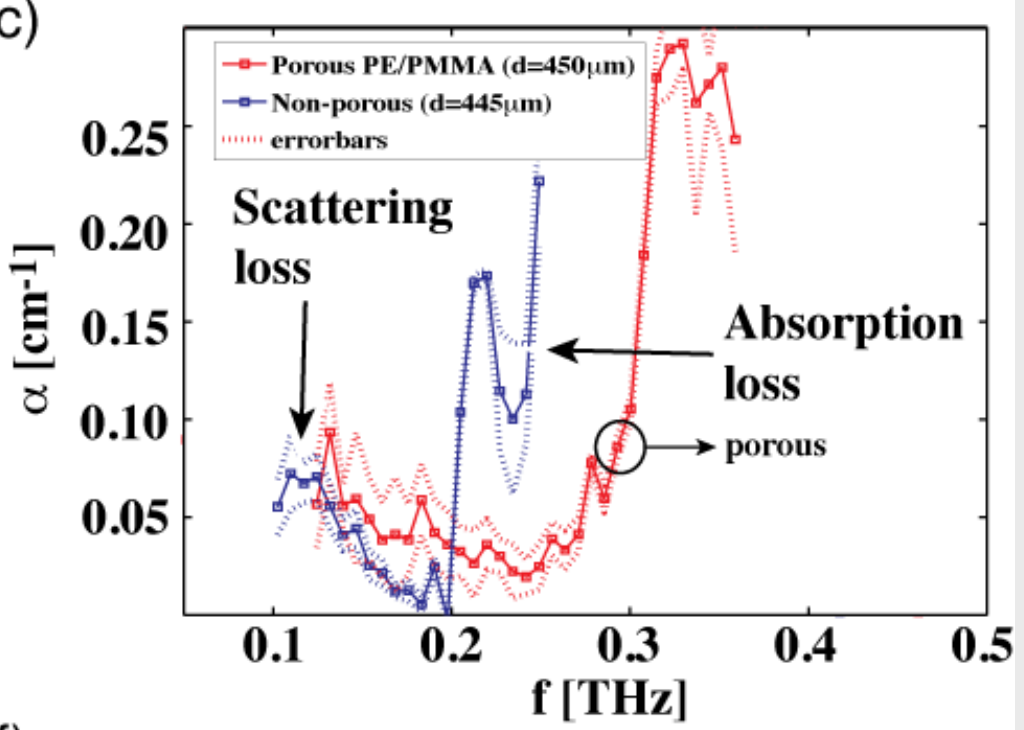

[A. Dupuis, A. Mazhorova, F. Desevedavy, M. Roze, M. Skorobogatiy, "Spectral characterization of porous dielectric subwaveleng THz fibers fabricated using a microstructured molding technique," Opt. Express 18, 13813-13828 (2010)] 


\section{Fabrication of porous fibers}

a) Sacrificial polymer technique

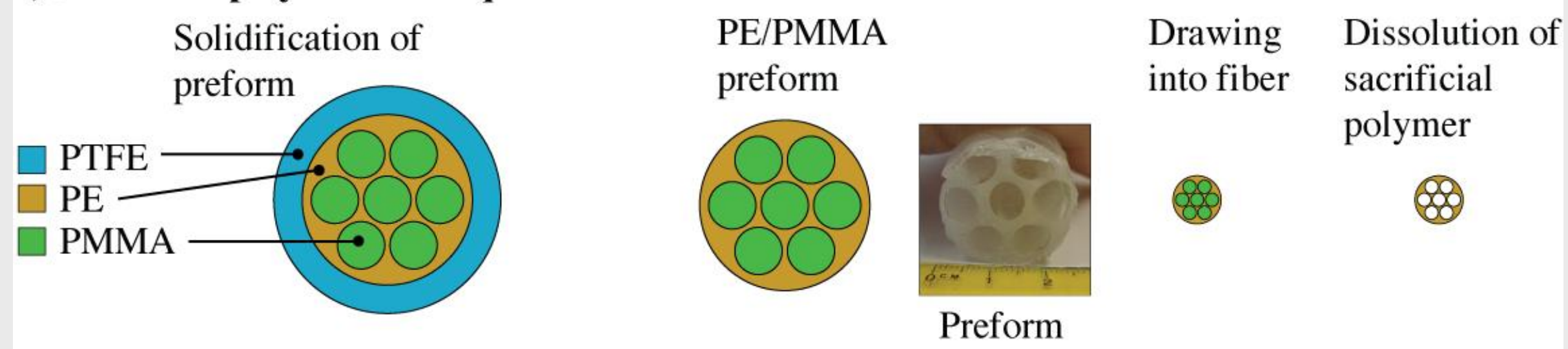

b) Microstructured molding technique

Molding of preform

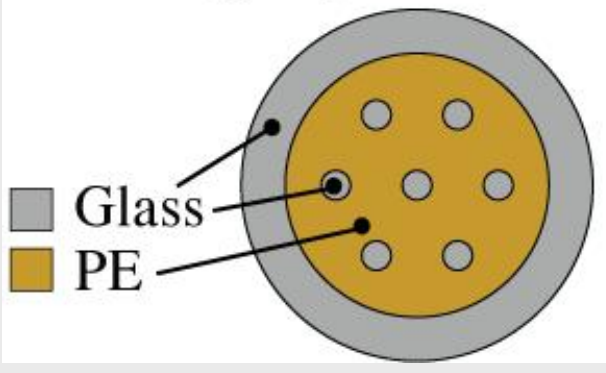

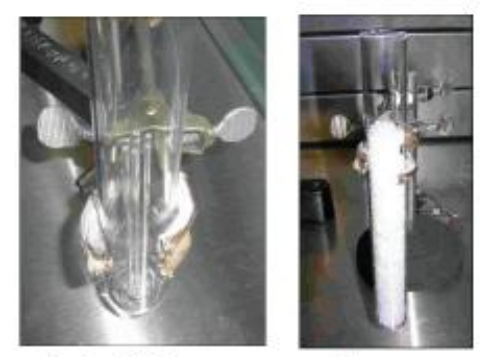

Mold + polymer
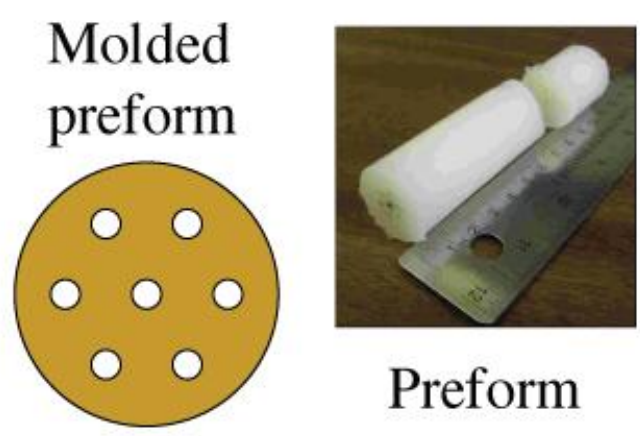

Drawing under pressure to inflate fiber holes

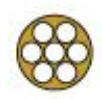

[A. Dupuis, A. Mazhorova, F. Désévédavy, M. Rozé and M. Skorobogatiy, Opt. Express, 18 (2010)] 
Packaging of subwavelength fibers: encapsulation

\section{within a protective tube}
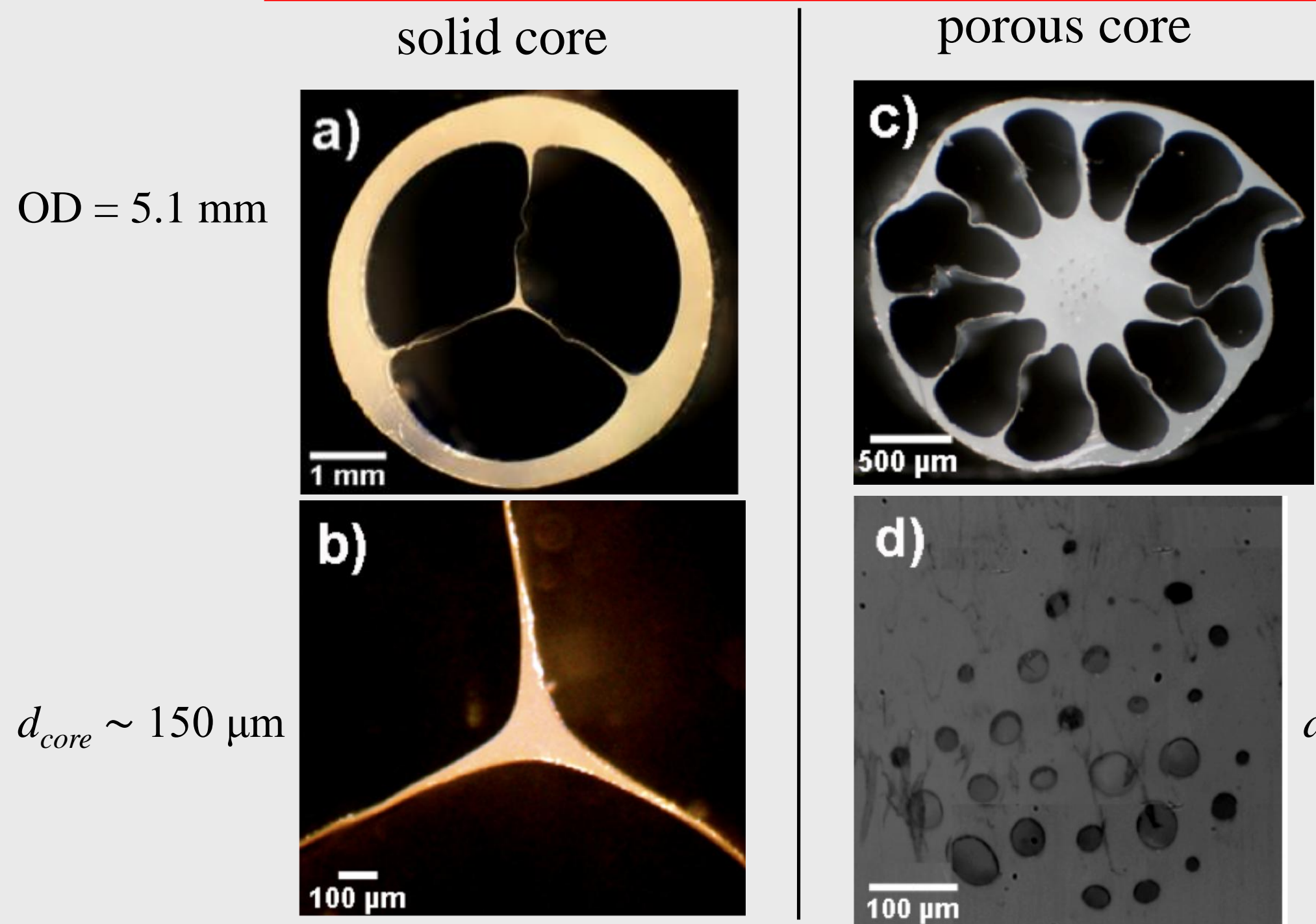

$\mathrm{OD} \sim 3.0 \mathrm{~mm}$

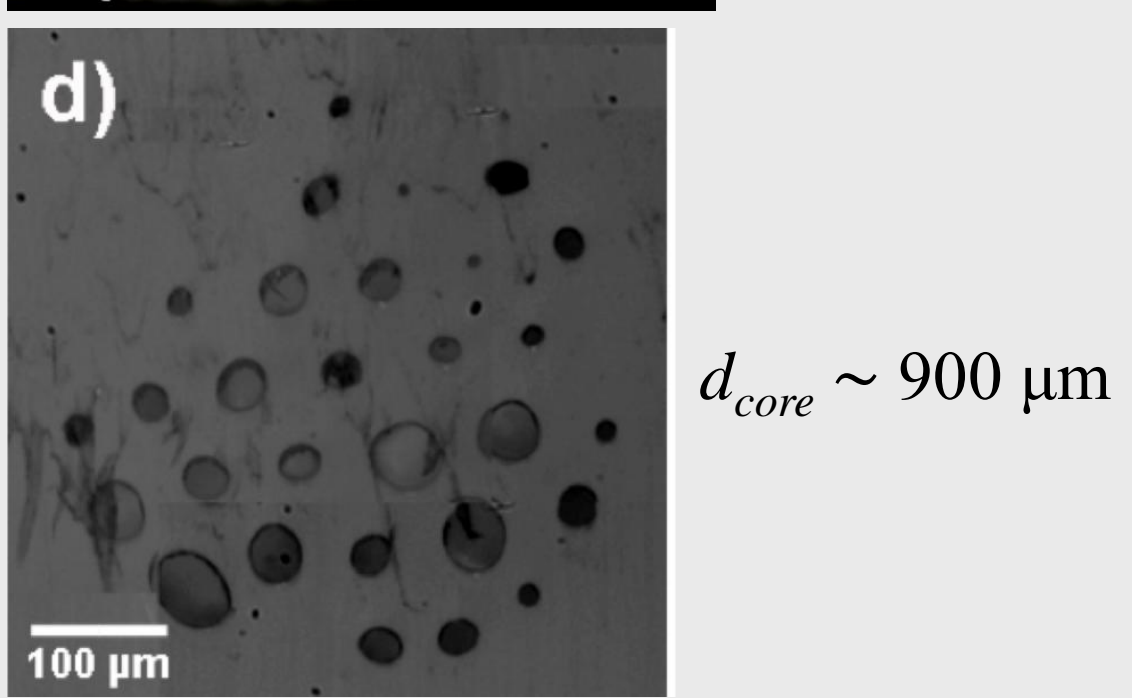

[M. Roze, B. Ung, A. Mazhorova, M. Walther, M. Skorobogatiy, "Suspended core subwavelength fibers: towards practical designs 4 r low-loss terahertz guidance," Optics Express 19, 9127 (2011) ] 


\section{THz near-field imaging setup}
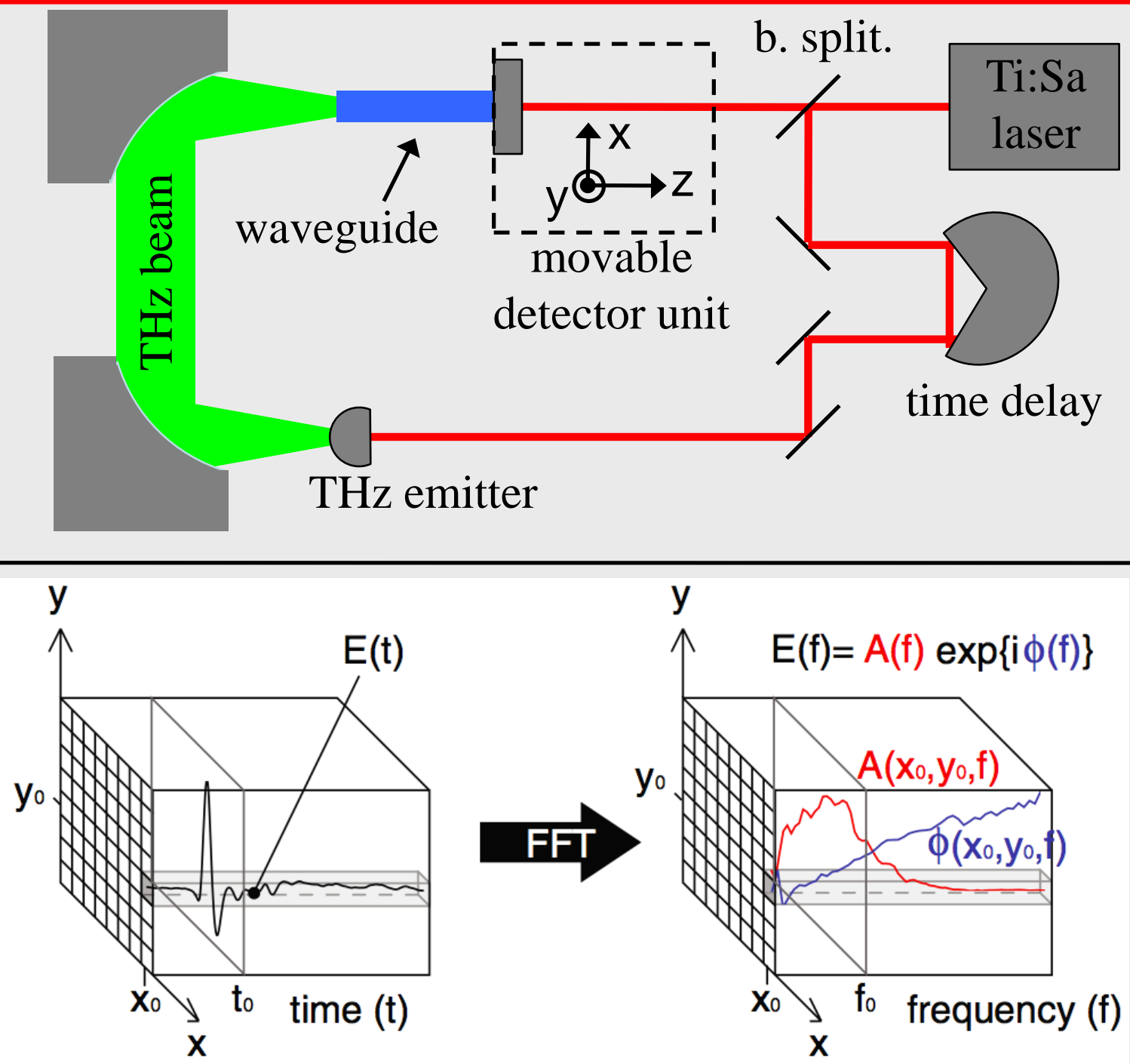

[M. Walther, and A. Bitzer, "Electromagnetic Wave Propagation Close to Microstructures Studied by Time and Phase-Resolved THz Near-Field Imaging," J Infrared Milli Terahz Waves (2011)] 
THz near-field imaging of output profile for the suspended solid core fiber

\section{$0.16 \mathrm{THz}$}
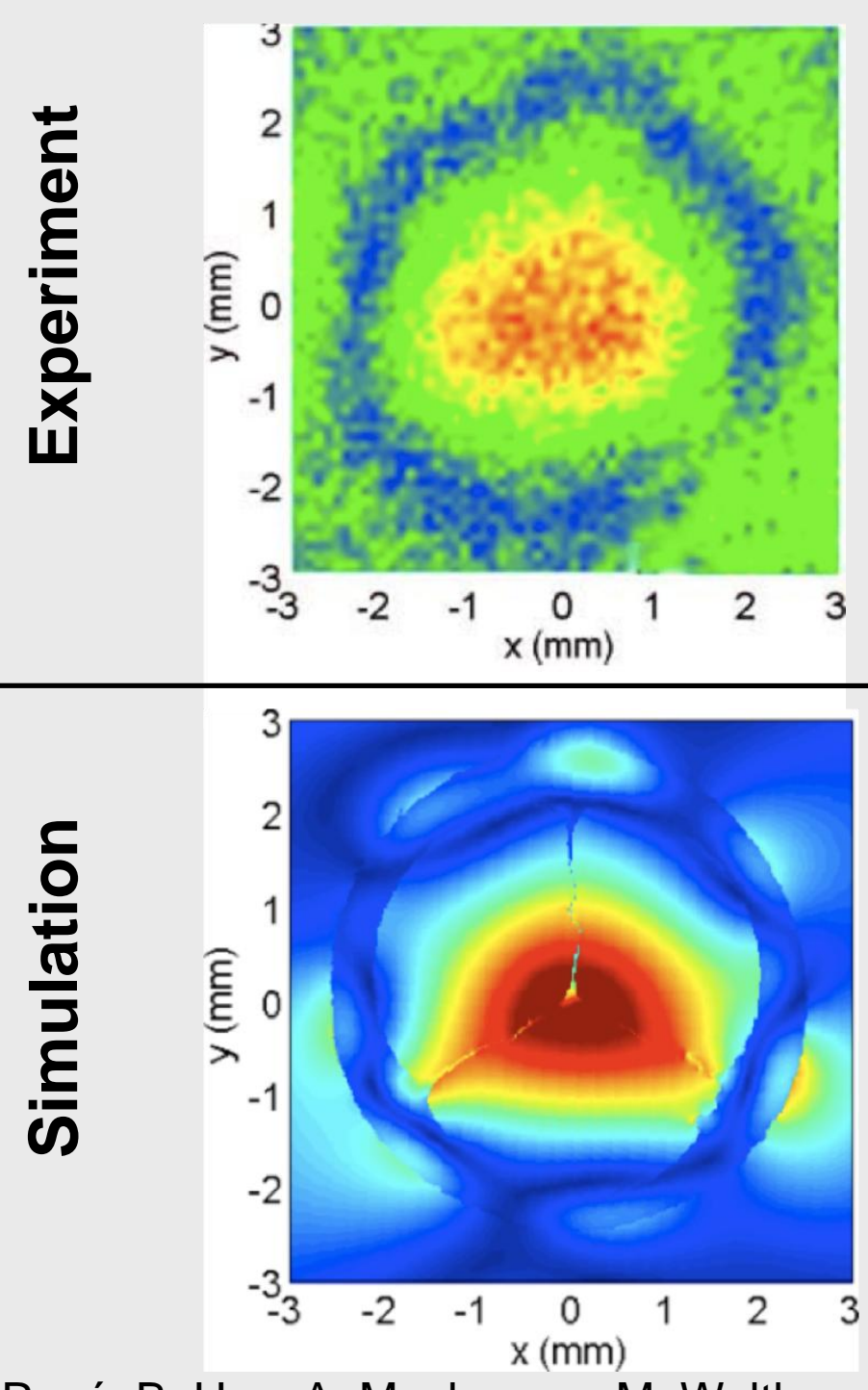

\section{$0.30 \mathrm{THz}$}
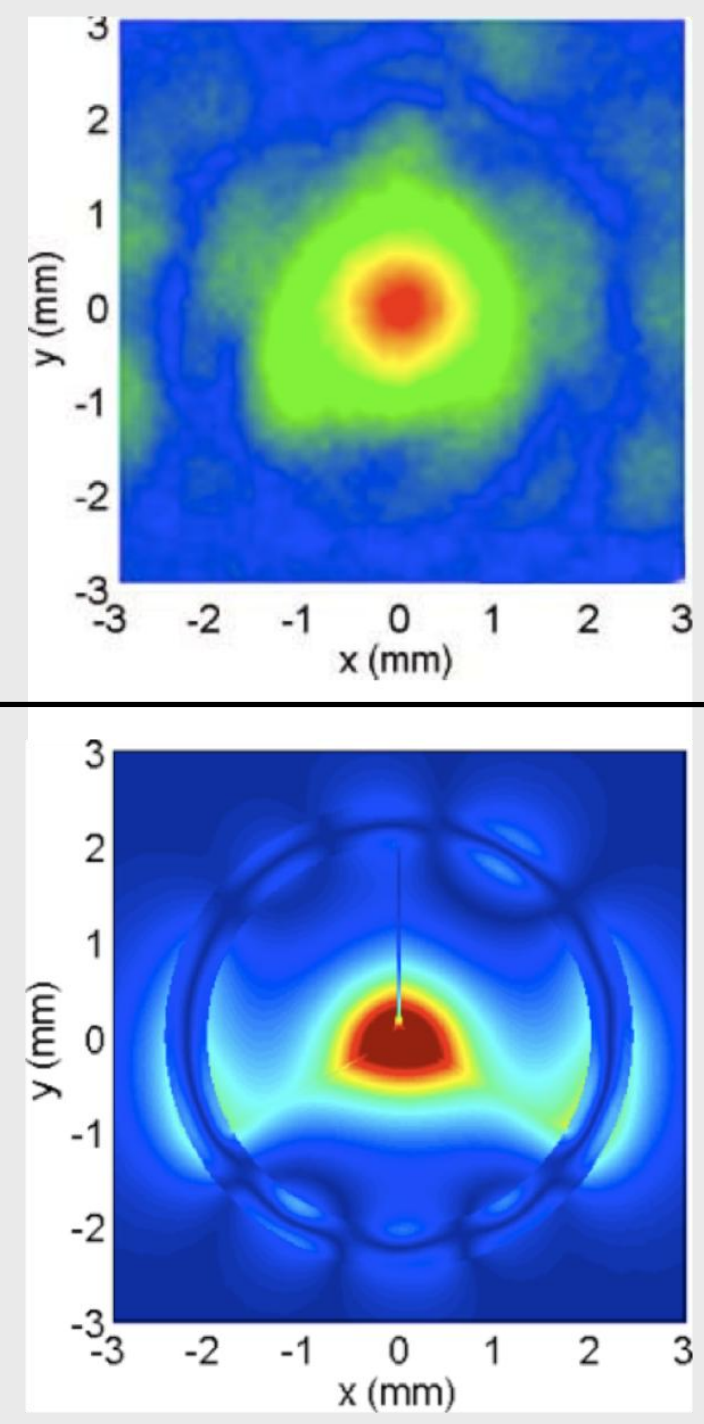

\section{$0.48 \mathrm{THz}$}

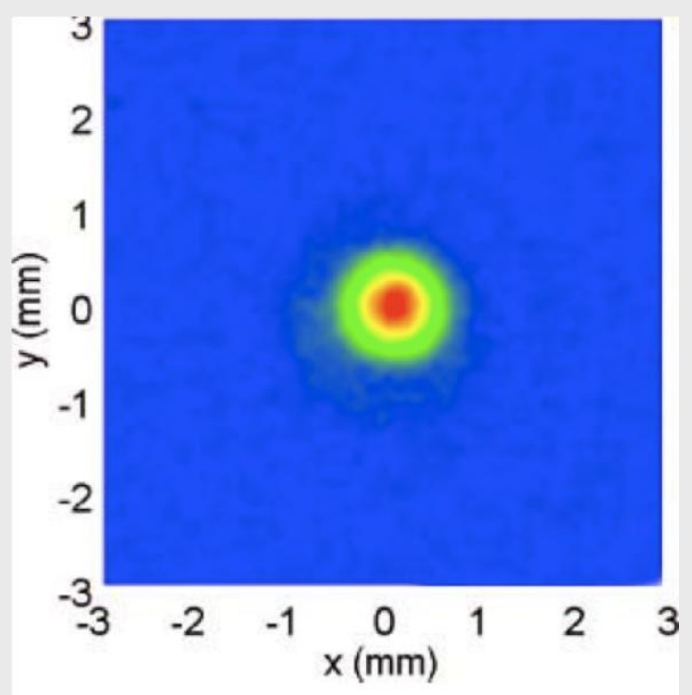

[M. Rozé, B. Ung, A. Mazhorova, M. Walther and M. Skorobogatiy, Opt. Express, 19 (2011)]

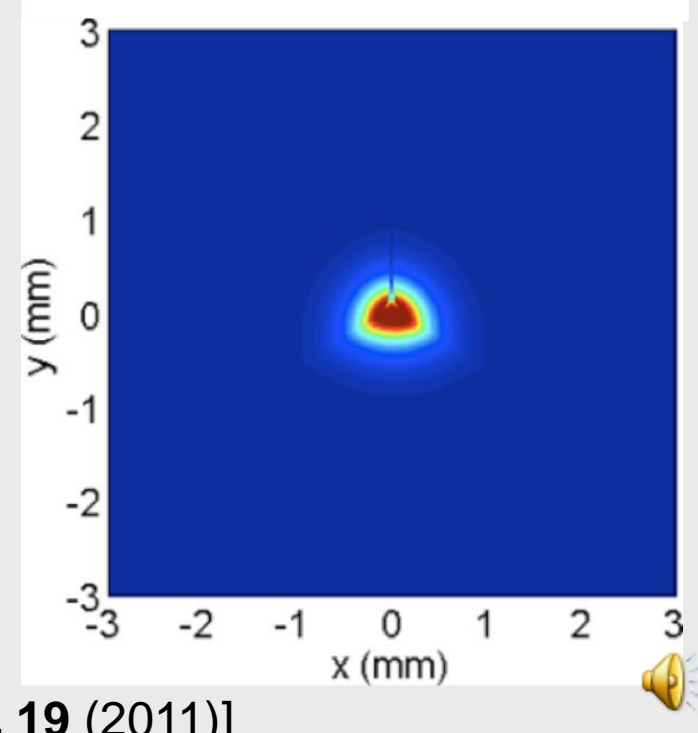




\section{Suspended fibers: transmission spectrum and propagation losses}

a)

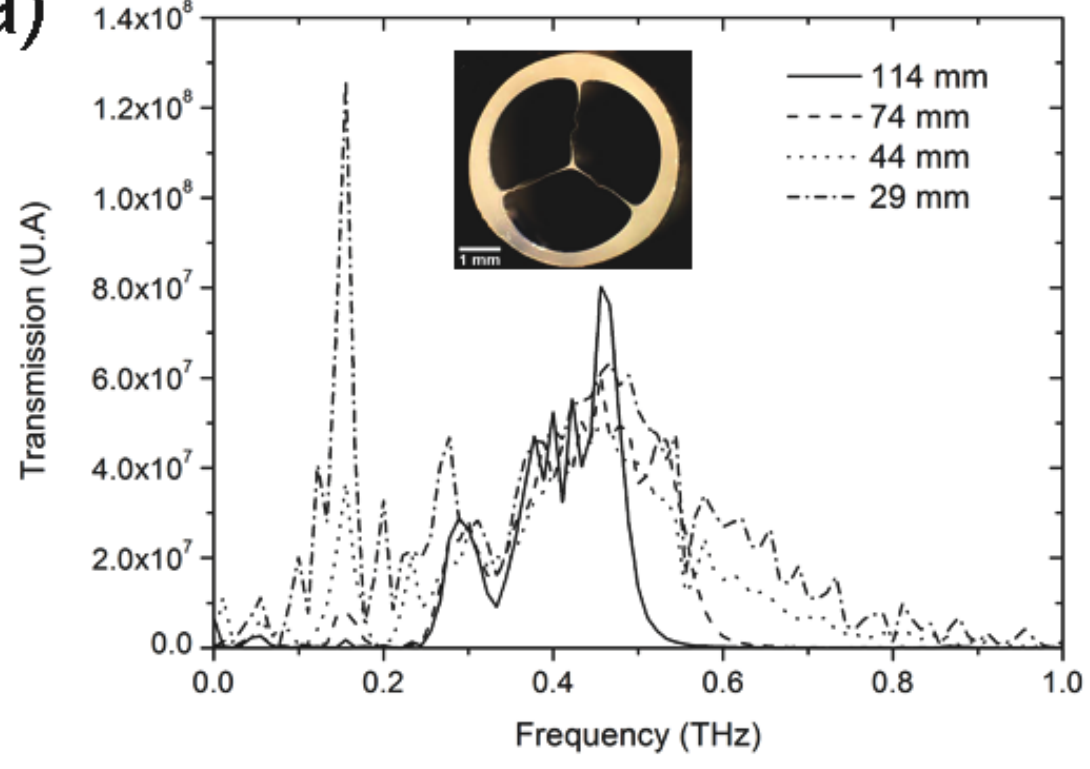

b)

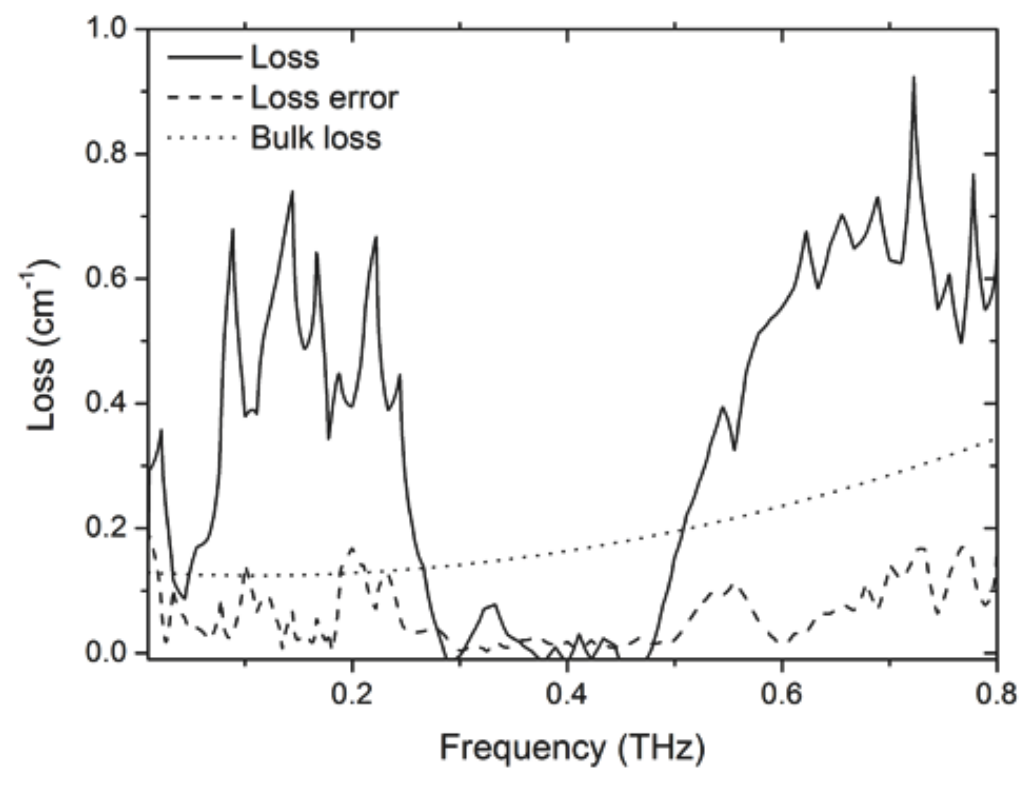

$\min$ loss $\leq 0.02 \mathrm{~cm}^{-1}$

[M. Rozé, B. Ung, A. Mazhorova, M. Walther and M. Skorobogatiy, Opt. Express, 19 (2011)] 


\section{Examples of devices based on subwavelength dielectric fibers: near field imaging}

Fiber-scanning THz imaging technique.

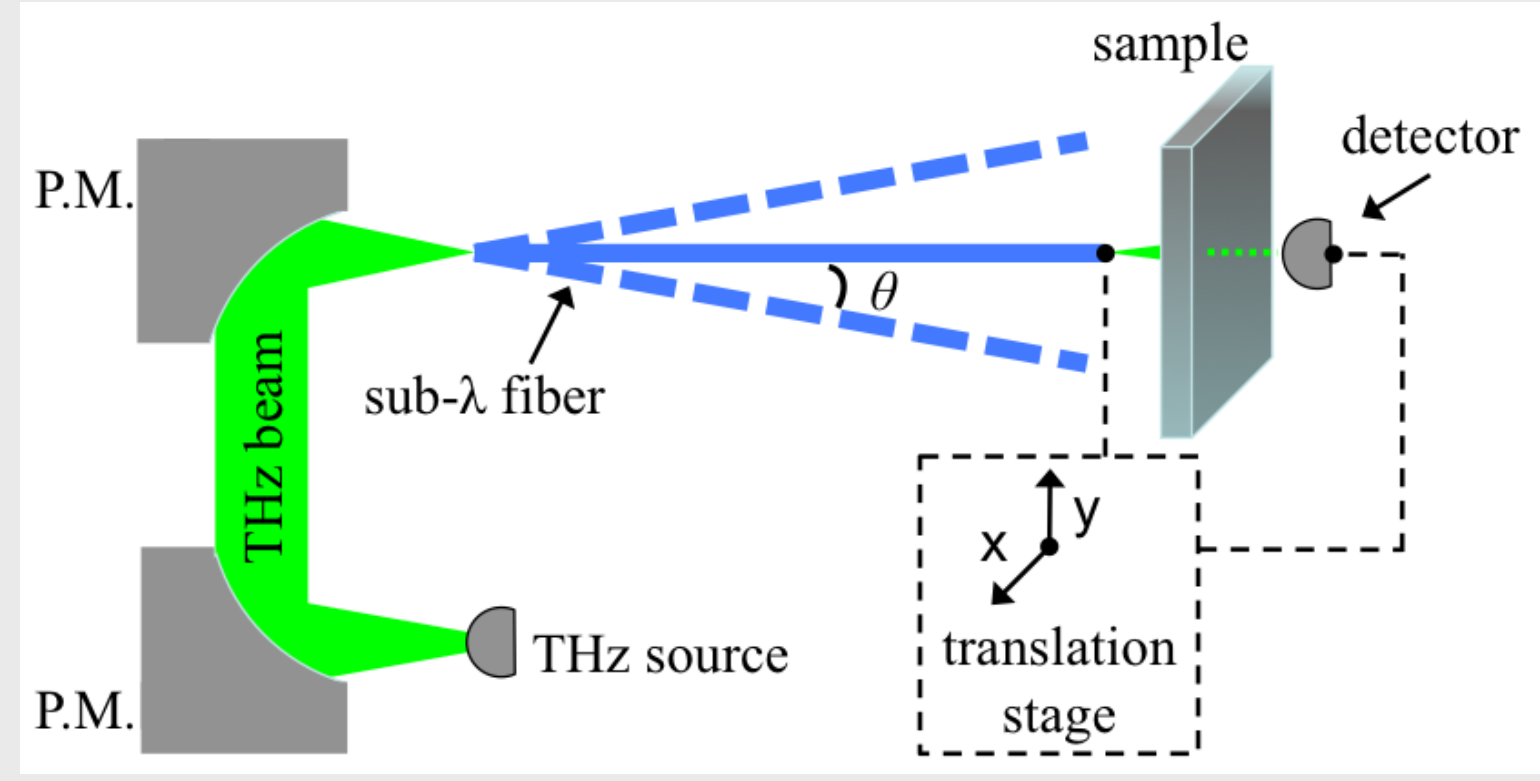

[J. Lu, C. Chiu, C. Kuo, C. Lai, H. Chang, Y. Hwang, C. Pan, and C. Sun, Appl. Phys. Lett., 92 (2008)] 


\section{dielectric fibers: non-destructive cut back}

\section{Fiber-based directional coupler for non-destructive cutback technique.}

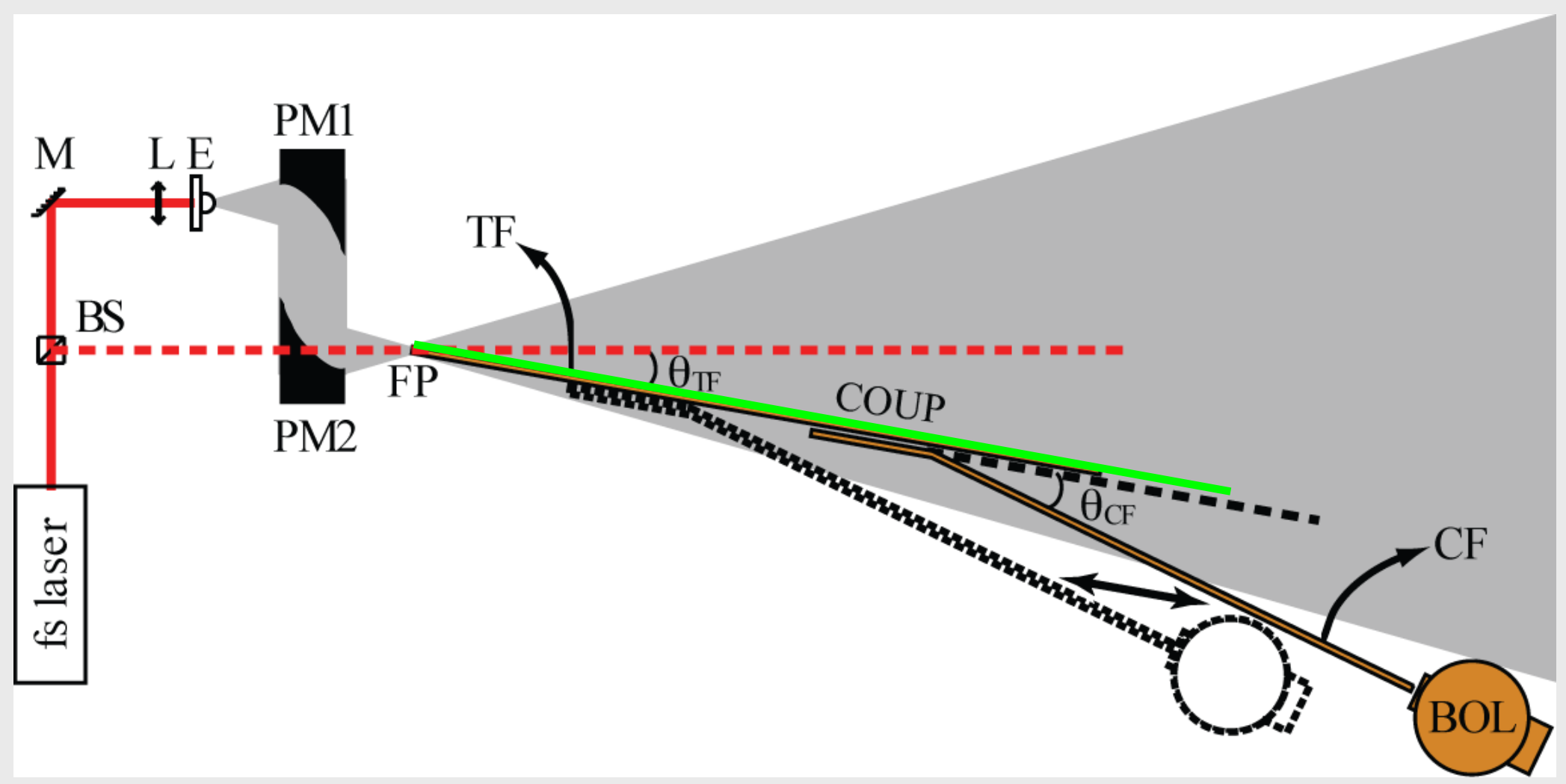

[A. Dupuis, J.-F. Allard, D. Morris, K. Stoeffler, C. Dubois, and M. Skorobogatiy, "Fabrication and THz loss measurements of porot subwavelength fibers using a directional coupler method," Opt. Express 17, 8012-8028 (2009).] 


\section{Plastic fibers for terahertz waves}
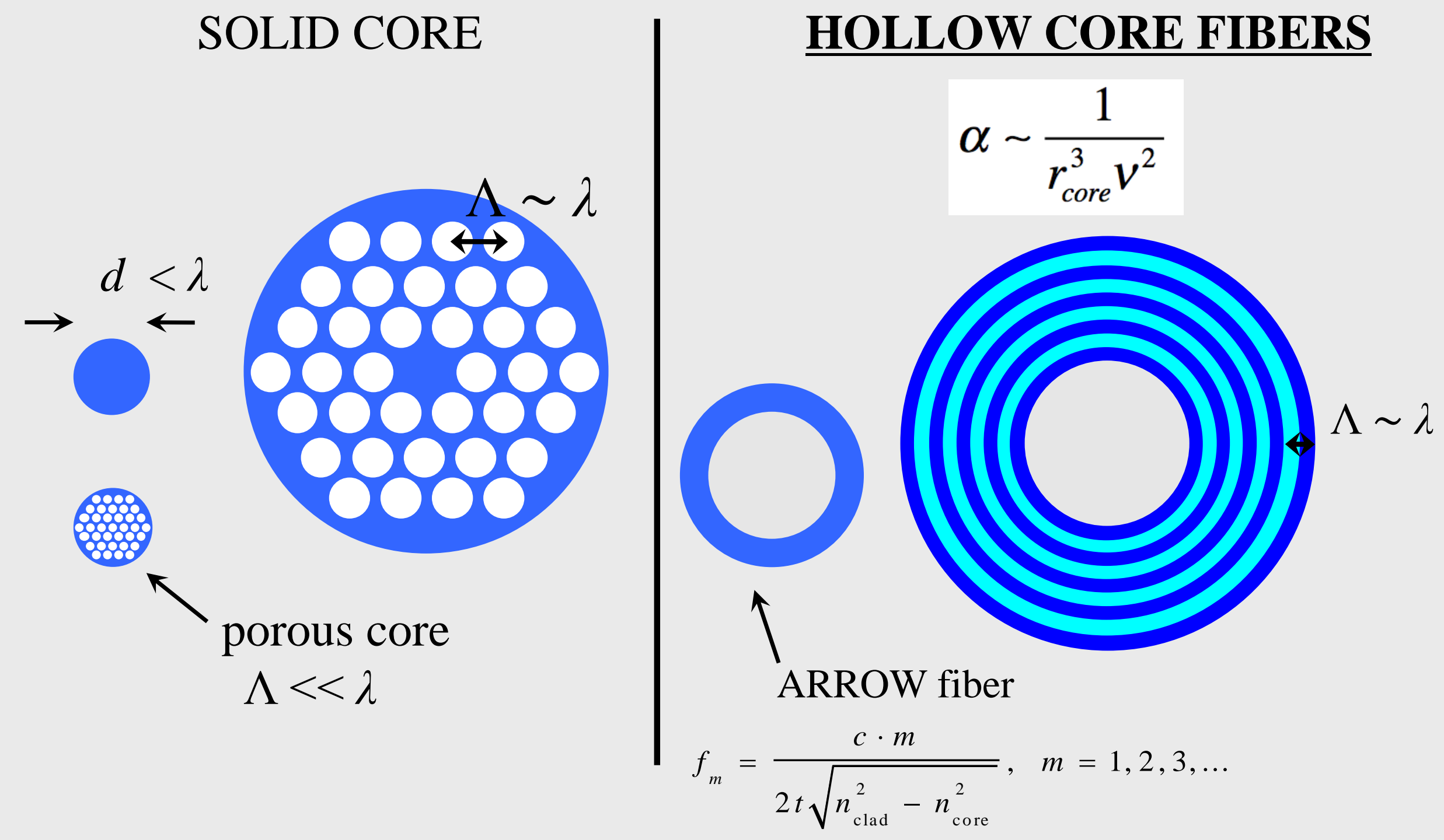

\section{HOLLOW CORE FIBERS}

$$
\alpha \sim \frac{1}{r_{\text {core }}^{3} v^{2}}
$$

$$
\Lambda<<\lambda
$$



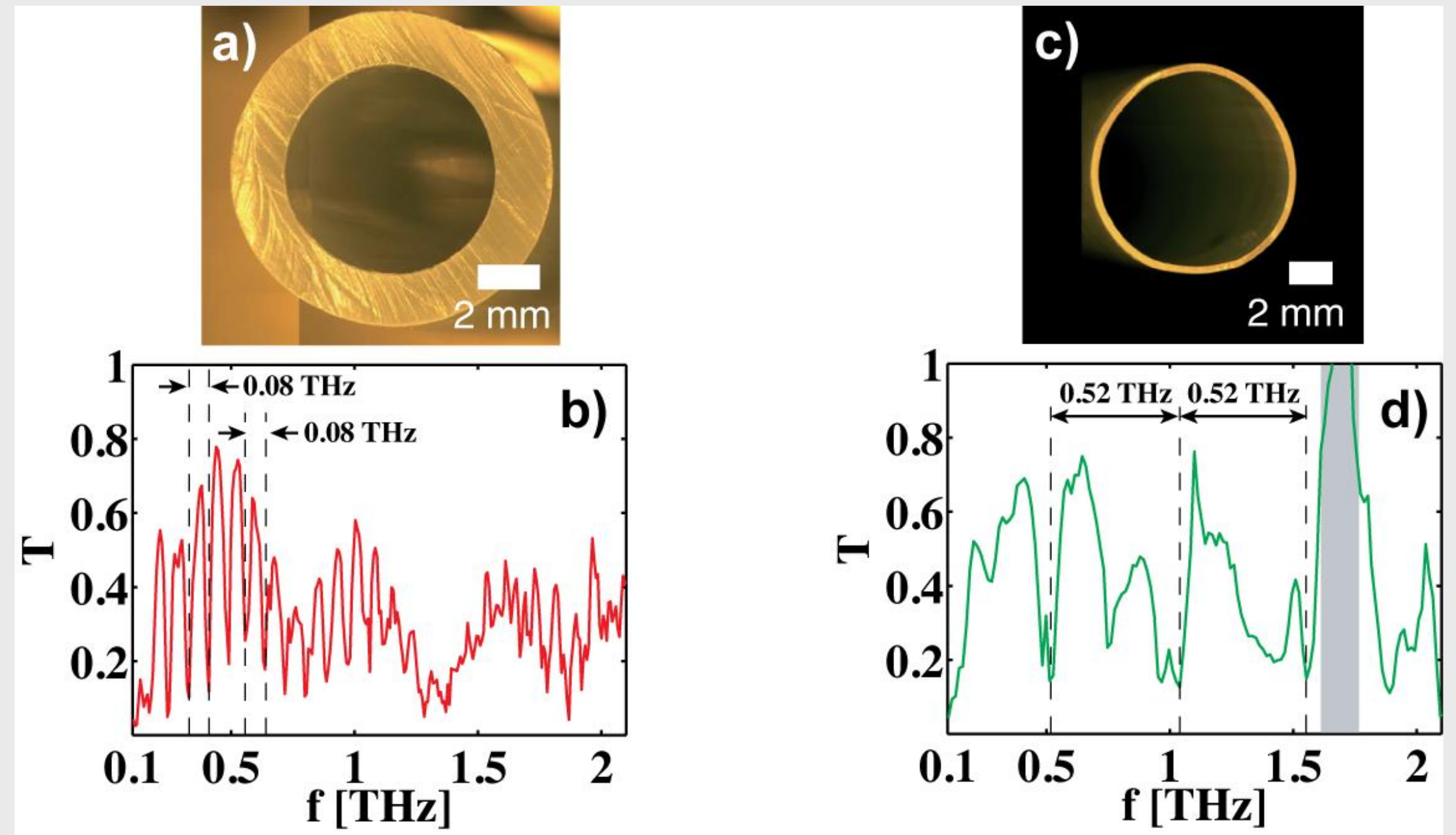

[A. Dupuis, K. Stoeffler, B. Ung, C. Dubois, and M. Skorobogatiy, "Transmission measurements of hollow-core THz Brag 6$)^{3}$ fibers," J. Opt. Soc. Am. B 28, 896 (2011) ] 


\section{Optical properties of the polyethylene $(\mathrm{PE}) / \mathrm{TiO}_{2}$ compounds}

\section{$\mathrm{TiO}_{2}$-doped PE optical properties}

Refractive index

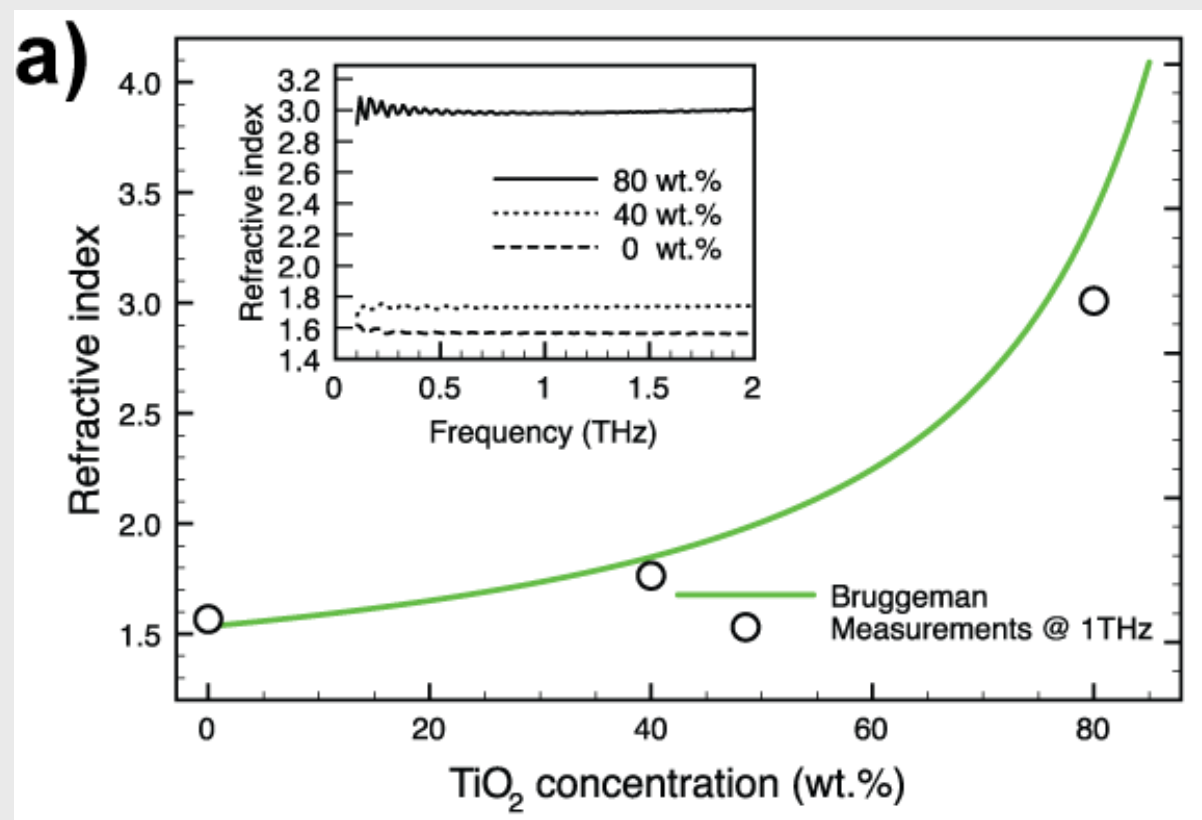

Absorption coefficient

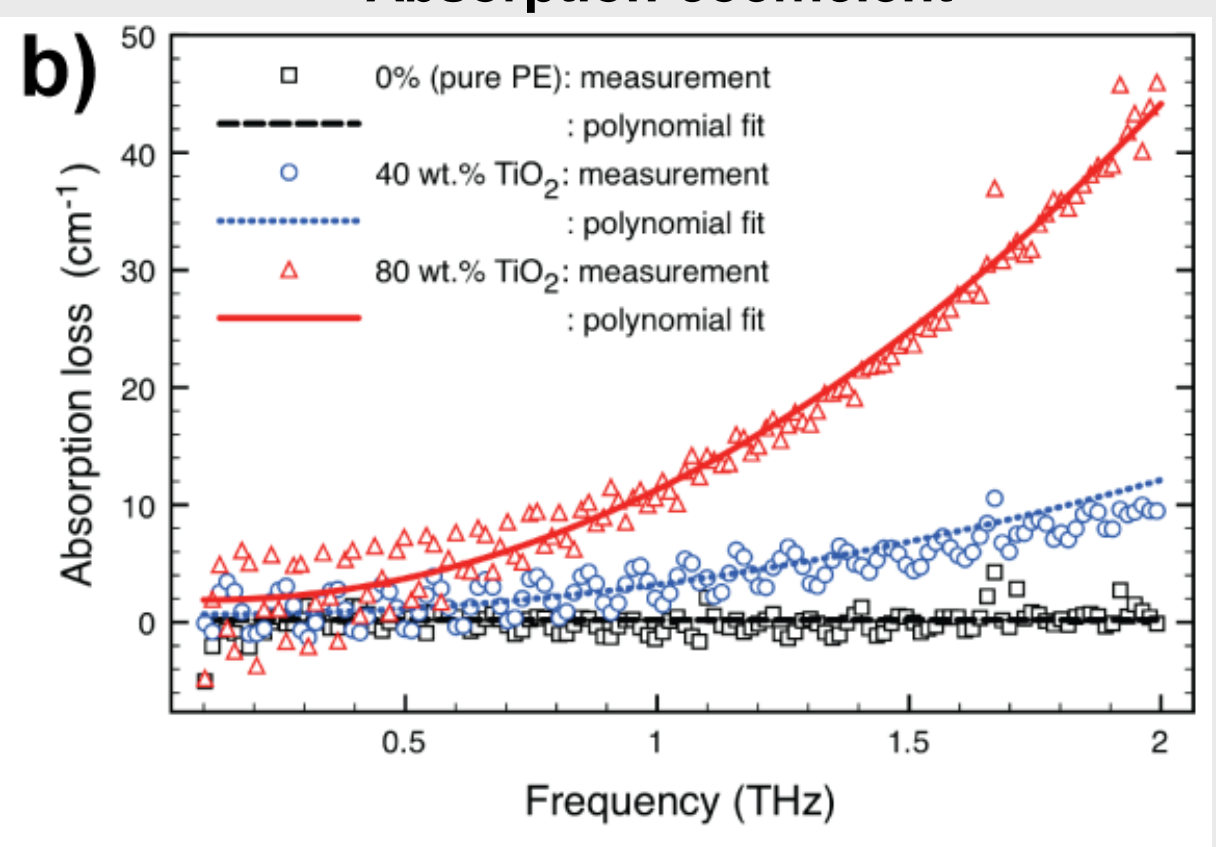

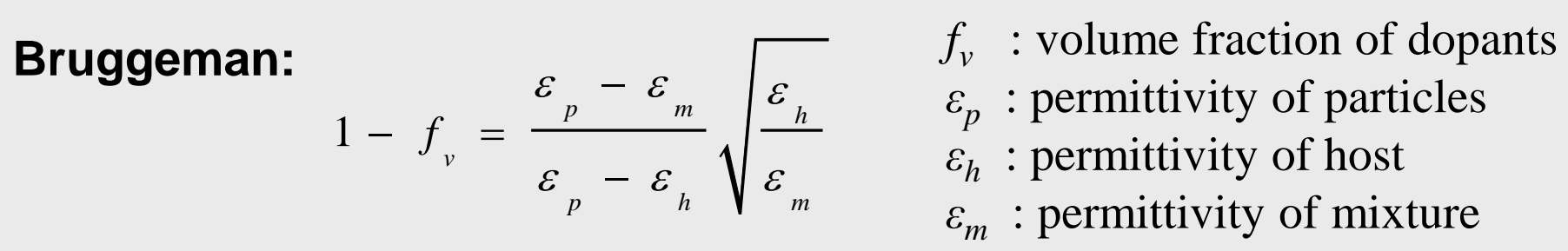

[B. Ung, A. Dupuis, K. Stoeffler, C. Dubois, and M. Skorobogatiy, J. Opt. Soc. Am. B, 28 (2011)] 


\section{Fabrication of plastic Bragg fibers}

Air-polymer Bragg fiber:

a) Ideal structure

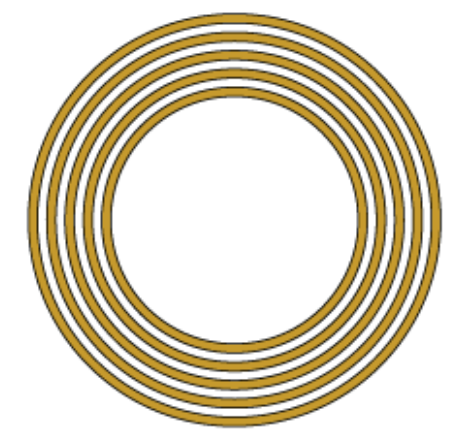

b) Rolling film with powder

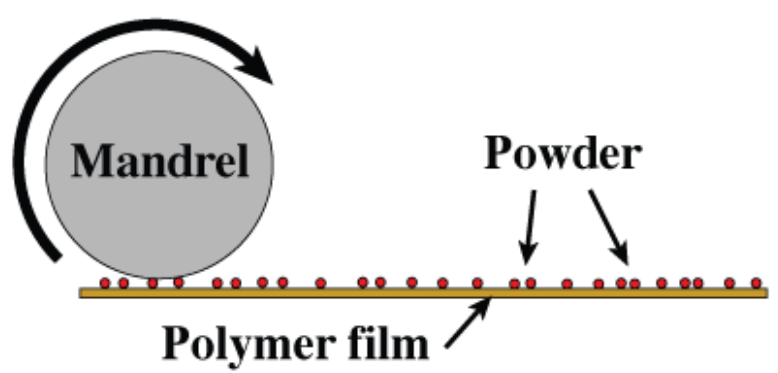

c) Experimental structure

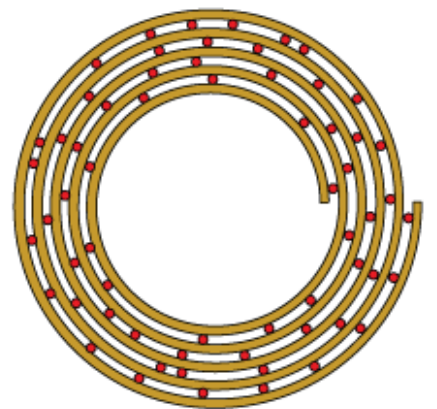

Doped-polymer Bragg fiber:

d) Ideal structure

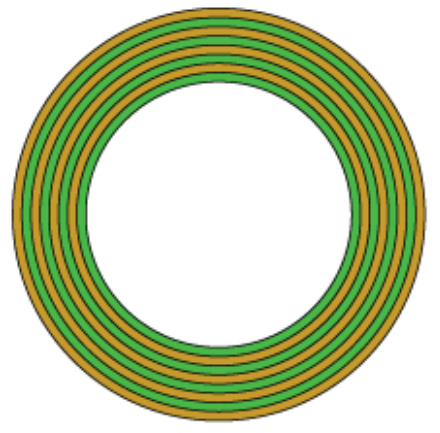

e) Pressing films into bilayer Rolling bilayer film

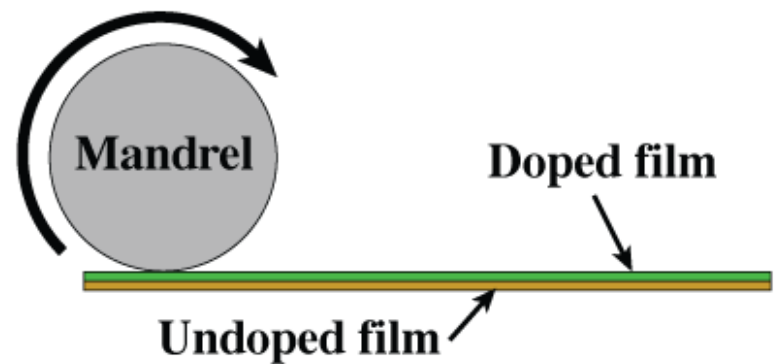

f) Experimental structure

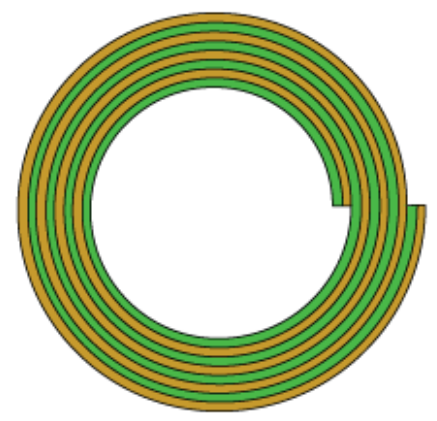

[A. Dupuis, K. Stoeffler, B. Ung, C. Dubois, and M. Skorobogatiy, J. Opt. Soc. Am. B, 28 (2011)] 


\section{Transmission of plastic Bragg fibers}

a)

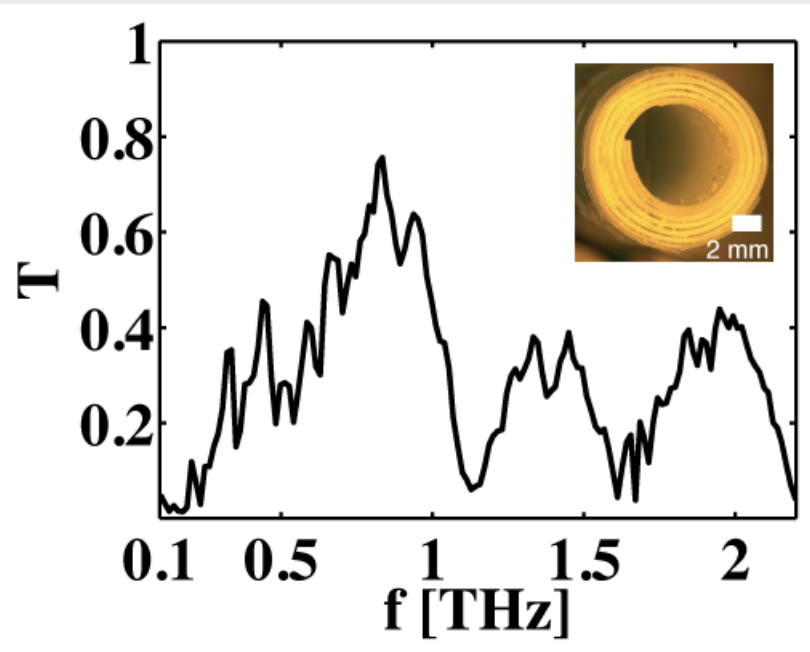

b)

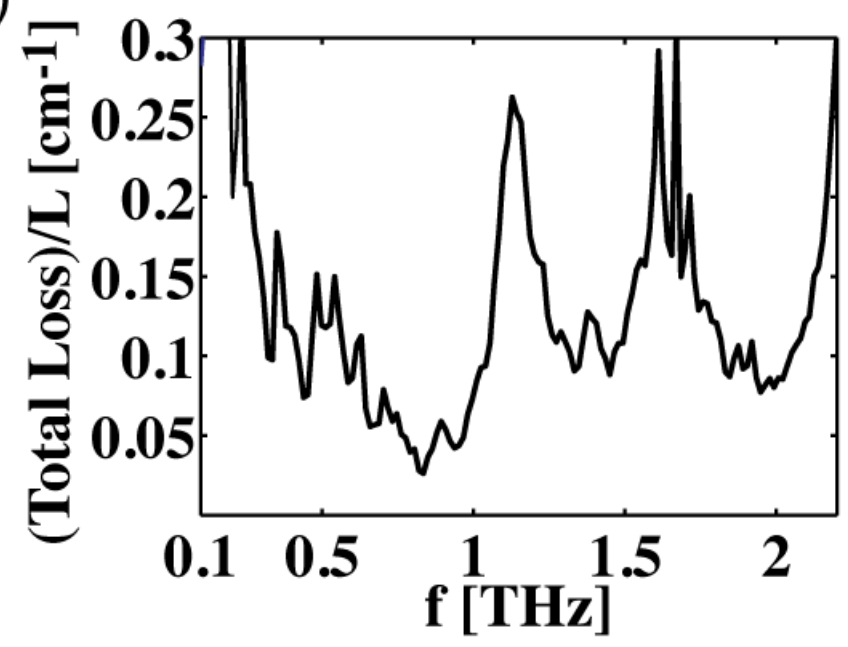

c)

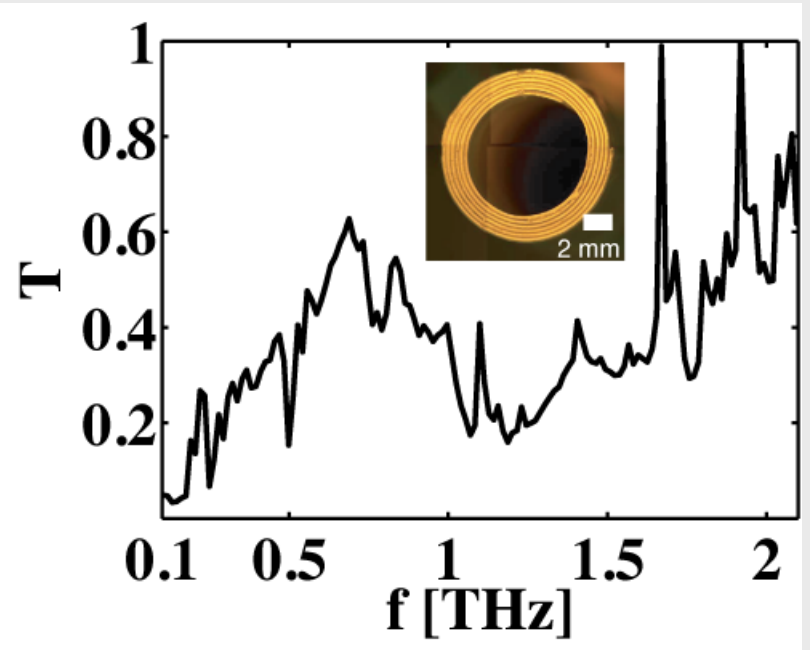

d)

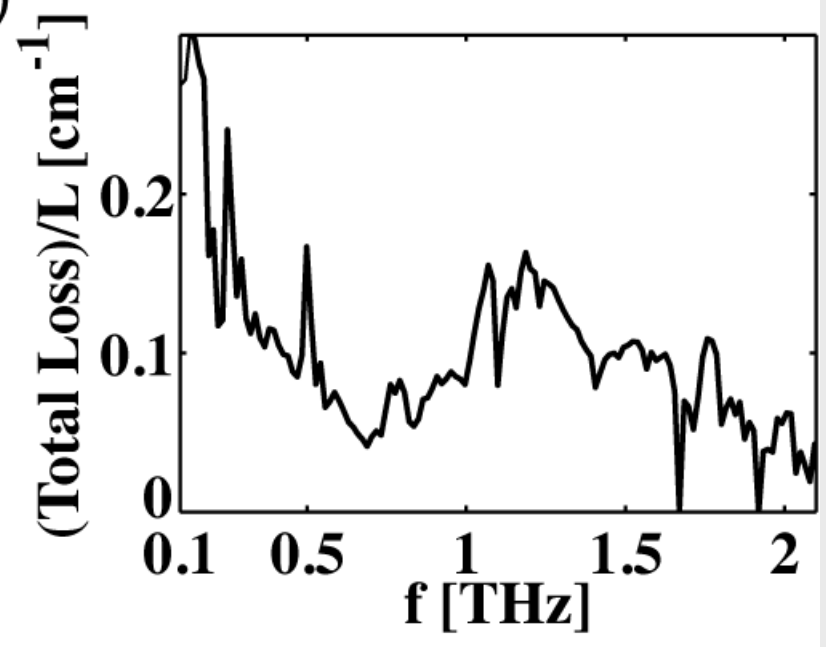

[A. Dupuis, K. Stoeffler, B. Ung, C. Dubois, and M. Skorobogatiy, J. Opt. Soc. Am. B, 28 (2011)] 


\section{Composite terahertz materials: fabrication}

Consecutive stack-and-draw technique towards fabrication of micro(-nano) wire arrays

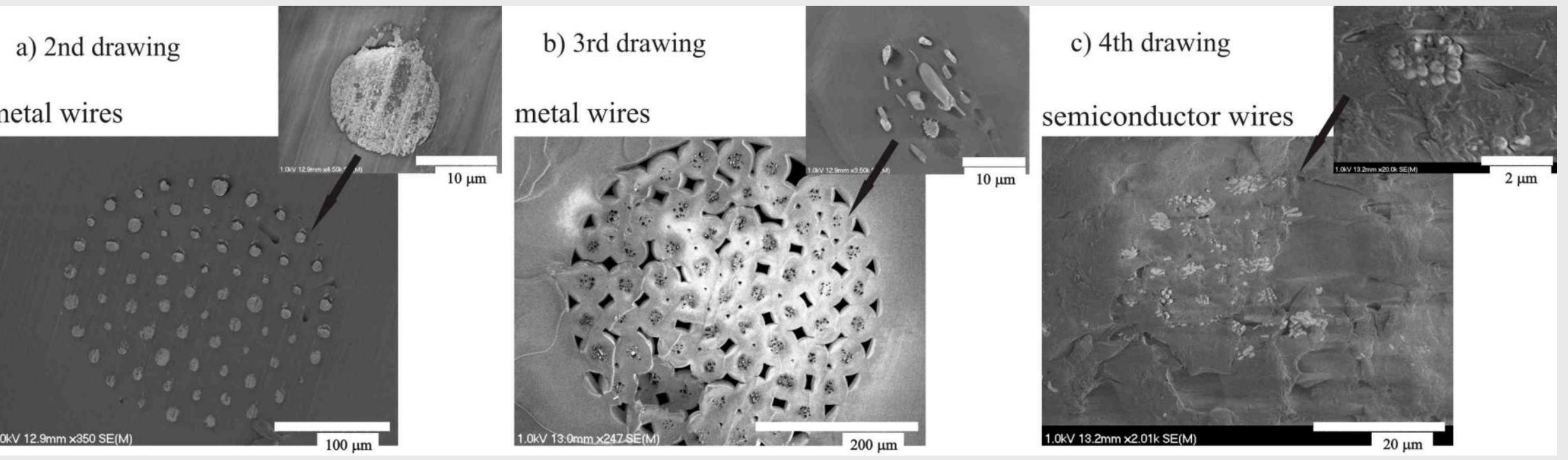

[A. Mazhorova, J. Gu, A. Dupuis, M. Peccianti, O. Tsuneyuki, R. Morandotti, H. Minamide, M. Tang, Y. Wang, He Ito, and M. Skorobogatiy, Opt. Express, 18 (2010)] 


\section{Composite terahertz materials: fabrication}

\section{Planar metamaterial film fabrication by pressing fibers containign wire arrays}

a)

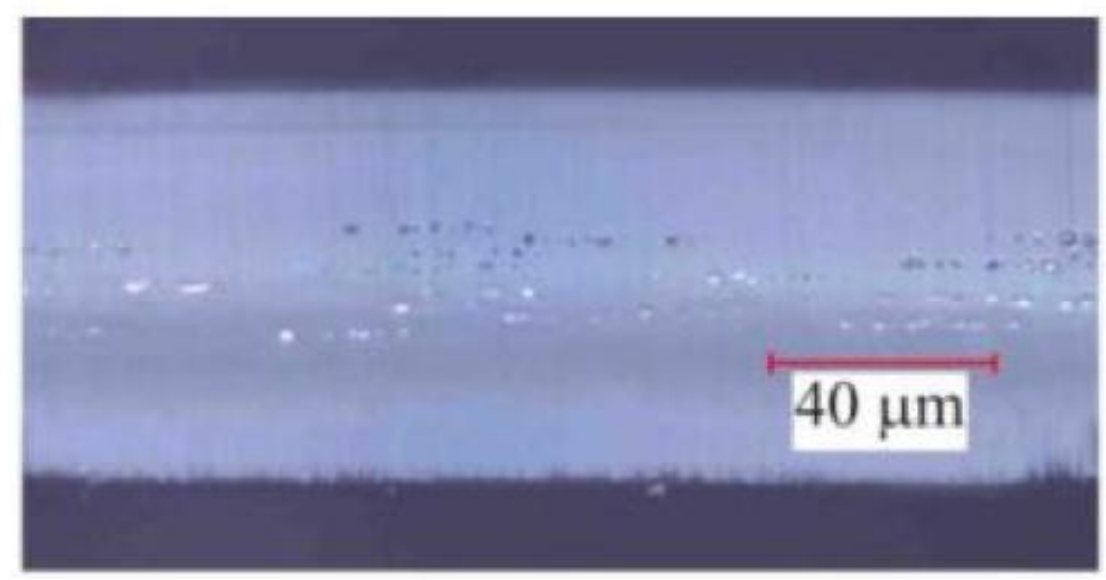

b)

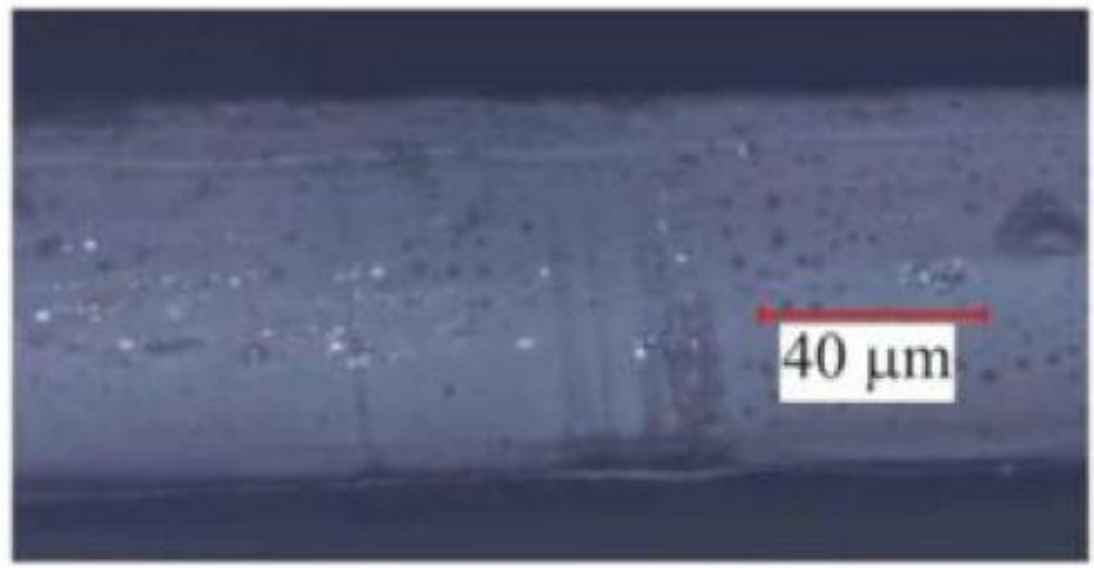

c)

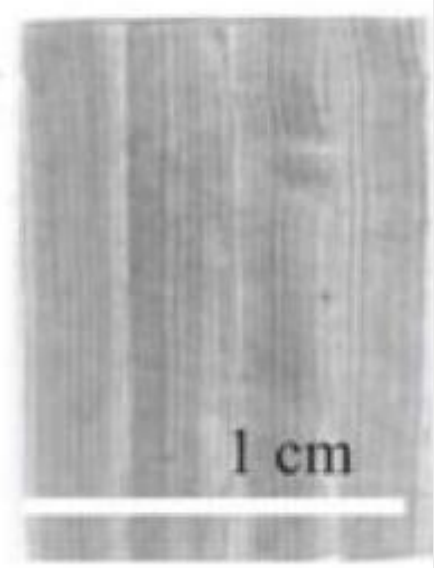

d)

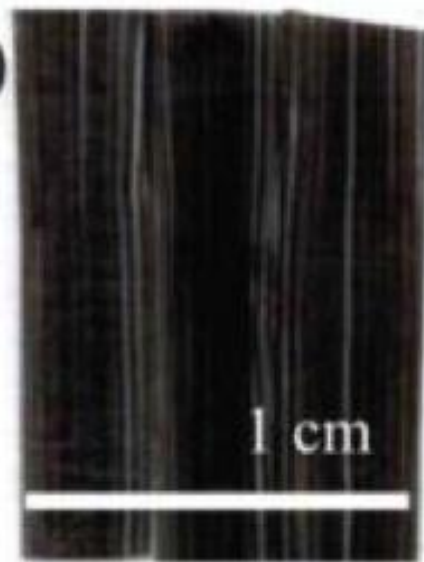

[A. Mazhorova, J. Gu, A. Dupuis, M. Peccianti, O. Tsuneyuki, R. Morandotti, H. Minamide, M. Tang, Y. Wang, Ha Ito, and M. Skorobogatiy, Opt. Express, 18 (2010)] 


\section{Composite terahertz materials: optical properties}
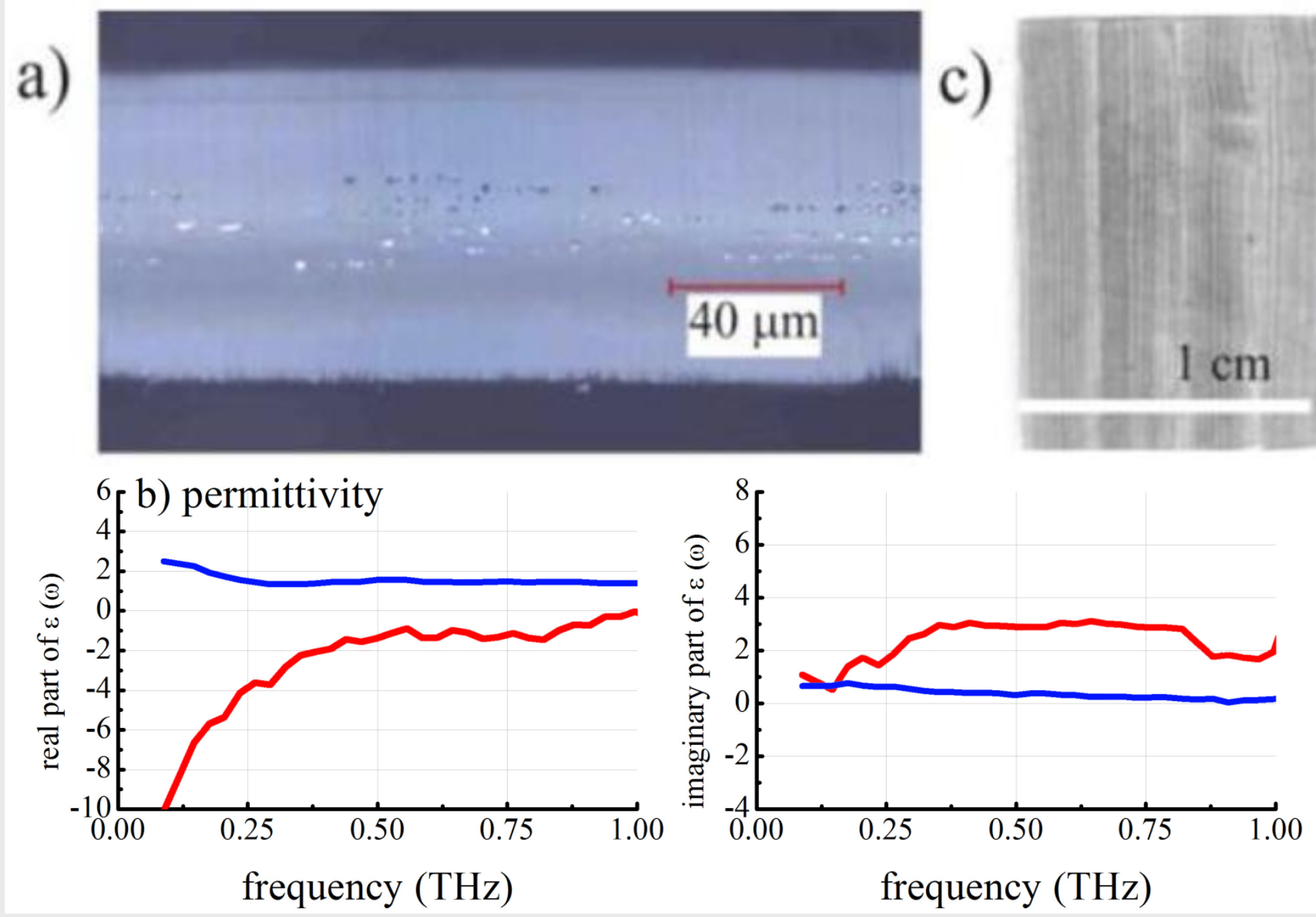

[A. Mazhorova, J. Gu, A. Dupuis, M. Peccianti, O. Tsuneyuki, R. Morandotti, H. Minamide, M. Tang, Y. Wang, H] Ito, and M. Skorobogatiy, Opt. Express, 18 (2010)] 


\section{for waveguide measurements}

a)

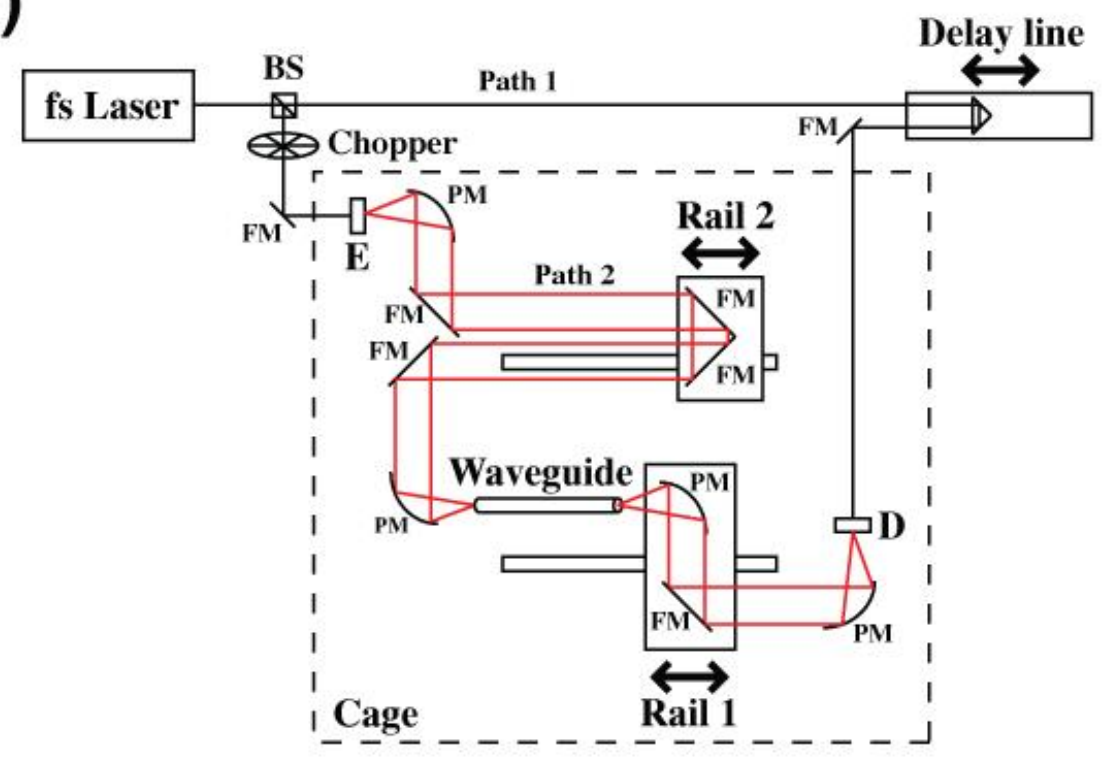

b)

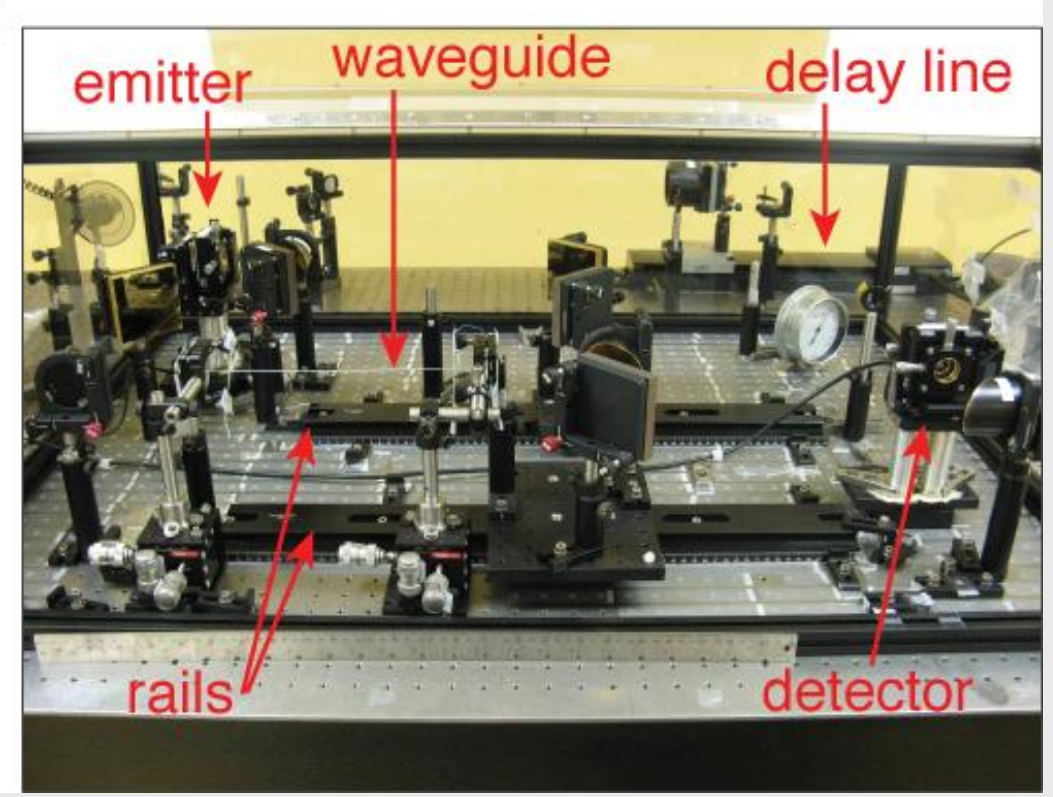

[A. Dupuis, A. Mazhorova, F. Désévédavy, M. Rozé and M. Skorobogatiy, Opt. Express, 18 (2010)] 


\section{Conclusions (subwavelength fibers)}

- To counteract material bulk absorption losses, the most effective approach is to minimize the fraction of power guided in lossy material regions: subwavelength fibers OR hollow-core fibers

- Compared to a solid core fiber of the same diameter, porous subwavelength fiber enables higher fraction of light to be guided in the low-loss air region. Transmission window of a porous fiber is, therefore, broader and shifted to higher frequencies.

- Compared to a solid core fiber of the same diameter, porous subwavelength fiber show lower group velocity dispersion, while its bending loss is superior to a solid core fiber due to high confinement of light in the porous air core.

- Packaging of fibers is crucial for practical applications:

-protective tubing shields core-guided mode from interacting with the environment -allows to forgo a purging cage by filling directly fiber cladding with a dry gas -enables direct and convenient handling of fibers during experiments 


\section{Conclusions (ARROW, Bragg fibers, new THz materials)}

- Low-loss THz guiding possible in ARROW fibers. Thinner capillaries = wider trasmission windows.

- Bragg fibers with thicker cladding confers greater mechanical stability compared to the thin-walled ARROW fibers, provides stronger modal confinement, and consequently, lower bending losses and reduced sensitivity to the environment.

- Possible to obtain very wide bandgaps with Bragg fibers provided that a high-refractive-index contrast is present in the bilayers of the periodic reflector.

- Composite $\mathrm{THz}$ materials based on polymers doped with high-index particles OR polymers with embedded metallic/semiconductor wires.

- Metallic micro/nano-wire media enables design of artificial materials with tunable refractive index and remarkable polarization properties. 


\section{Acknowledgements}

- The Natural Sciences and Engineering Research Council of Canada

Fonds de recherche

sur la nature

et les technologies

Québec :

Canada Research
Chairs

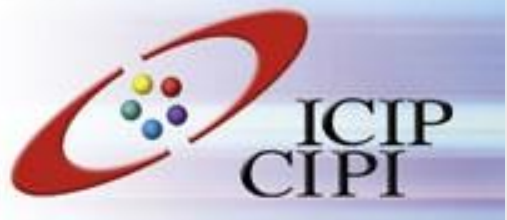

- Fonds Québécois de la Recherche sur la Nature et les Technologies

- Canada Research Chair Foundation

- Canadian Institute for Photonics Innovations 